\title{
Characterization of a novel bacterial cellulose producer for the production of eco-friendly piezoelectric-responsive films from a minimal medium containing waste carbon
}

\author{
Rahul Mangayil (D) Antti J. Rissanen · Arno Pammo • Dieval Guizelini • \\ Pauli Losoi · Essi Sarlin · Sampo Tuukkanen · Ville Santala
}

Received: 3 August 2020/Accepted: 20 October 2020/Published online: 6 November 2020

(C) The Author(s) 2020

\begin{abstract}
Bacterial cellulose (BC) is a biodegradable polymer that benefits in purity, crystallinity and superior optical, structural and mechanical properties. Such properties facilitate BC to replace the conventional non-biodegradable materials used, for instance, in sensing applications. However, BC production is largely conducted in conventional medium containing model substrates and complex carbon-containing compounds. Aiming towards the production of ecofriendly piezoelectric-responsive $\mathrm{BC}$ films, we isolated and characterized a novel bacterial strain affiliated to Komagataeibacter rhaeticus. The K. rhaeticus ENS9a strain synthesized BC in minimal medium
\end{abstract}

Electronic supplementary material The online version of this article (https://doi.org/10.1007/s10570-020-03551-6) contains supplementary material, which is available to authorized users.

R. Mangayil $(\varangle) \cdot$ A. J. Rissanen ·

P. Losoi - E. Sarlin · V. Santala

Faculty of Engineering and Natural Sciences, Tampere

University, Tampere, Finland

e-mail: rahul.mangayil@tuni.fi

A. Pammo $\cdot$ S. Tuukkanen

Faculty of Medicine and Health Technology, Tampere

University, Tampere, Finland

D. Guizelini

Graduate Program in Bioinformatics, Sector of

Professional and Technological Education, Federal

University of Parana (UFPR), Curitiba,

PR, Brazil containing crude glycerol, generating a titer of $2.9 \pm 0.3 \mathrm{~g} / \mathrm{L} \mathrm{BC}$. This is, to the best of our knowledge, the highest $\mathrm{BC}$ titer reported from an unoptimized minimal medium containing crude glycerol. Interestingly, the films prepared from crude glycerol showed normal force and bending mode sensitivities of 6-11 pC/N and 40-71 pC/N, respectively, demonstrating a green platform to address both bioprocess waste valorization and implementation of cellulosebased alternatives for the non-sustainable and nonbiodegradable materials, such as fluoropolymers or lead containing piezoceramics, used in sensing applications. In silico genome analysis predicted genes partaking in carbohydrate metabolism, BC biogenesis, and nitrogen fixation/regulation. 


\section{Graphic abstract}

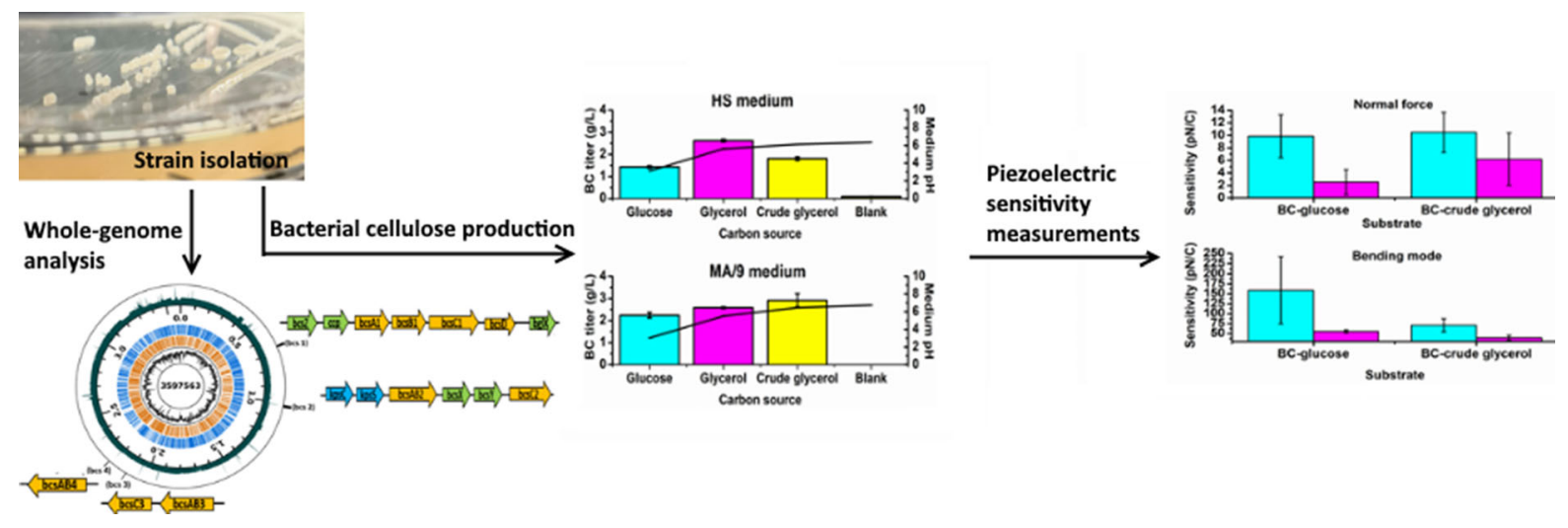

Keywords Bacterial cellulose - Strain selection · Komagataeibacter spp. · Crude glycerol · Piezoelectric material · Whole-genome analysis

\section{Introduction}

Cellulose is the most abundant biopolymer on earth and a versatile material significant in various fields of applications. However, harvesting the cellulose from biomass requires harsh pre-treatment steps with highenergy input, often generating aromatic lignin and/or toxic sulfoxides by-products.

Production of extracellular cellulose has been described in gram-negative aerobic bacterial species such as Komagataeibacter sp., Escherichia sp., Salmonella sp. (Schramm and Hestrin 1954; Shigematsu et al. 2005). Among bacteria, the most efficient cellulose producers are found in the genus Komagataeibacter (previously known as Acetobacter and Gluconacetobacter). In Komagataeibacter sp., the highly ordered bacterial cellulose (BC) is synthesized by the catalytic activities of glucokinase, phosphoglucomutase, UDP-glucose pyrophosphorylase and bacterial cellulose proteins $\mathrm{B} c s \mathrm{~A}, \mathrm{~B} \operatorname{csB}, \mathrm{B} \operatorname{csC}$ and $\mathrm{B} \operatorname{csD}$ [encoded by bacterial cellulose synthase (bcs) operon]. BC biogenesis commences via the binding of c-di-GMP to the PilZ domain of BcsA subunit, catalyzing the polymerization of UDP-glucose to $\beta$ 1,4-glucan units. The $\mathrm{BcsB}$ protein transports the synthesized glucan chain through the periplasmic space. The $\mathrm{BcsD}$ and $\mathrm{BcsC}$ proteins are involved in the formation of crystalline regions and extracellular export of the synthesized polysaccharide, respectively. The bcs operon is flanked with accessory genes $c c p A x$, $b c s Z, b g l x A, b c s X$ and $b c s Y$ encoding for cellulose complementing factor protein, endo-1,4-glucanase, glucosidase, cellulose deacetylase and cellulose transacetylase, respectively. These accessory genes are reported to complement the bcs operon in polymerization of glucan chains, fibril packaging and cellulose crystallization (McNamara et al. 2015).

Unlike plant-based cellulose, BC is not complexed with lignin, hemicellulose or pectin and benefits in biodegradability and superior material properties. Furthermore, BC benefits in high level of purity and crystallinity (Lee et al. 2014). Owing to this, BC is extensively researched for its use in various applications (Mangayil et al. 2017; Vuorinen et al. 2018; Wang et al. 2019). However, its widespread application is hindered due to low production metrics such as yield and titer. To surpass this challenge both random mutagenesis and rational engineering approaches have been conducted in Komagataeibacter spp. (Hungund and Gupta 2010; Florea et al. 2016; Mangayil et al. 2017). Despite the advancements in genetic engineering, Komagataeibacter spp. are mainly cultivated in medium containing model substrates and carboncontaining compounds such as yeast extract, peptone, ethanol, and acetic acid (Kuo et al. 2015; Lu et al. 2020). To address this issue, studies have focused in using agro and industrial wastes as growth substrates (Carreira et al. 2011; Vazquez et al. 2013; Tsouko et al. 2015; Wu et al. 2019). However, in these studies the media to which the waste compounds were supplemented often contained other sources of carbon. 
Inclusion of such compounds restricts in elucidating the substrate's contribution towards BC synthesis.

Chemically defined media have been used to cultivate both gram-negative and gram-positive bacteria (Yuste 2000). For Komagataeibacter spp., several recipes of minimal growth medium are available. A medium composed of glucose, citric acid, $\mathrm{Na}_{2-}$ $\mathrm{HPO}_{4}, \mathrm{KCI}, \mathrm{MgSO}_{4}$, and nicotinamide to cultivate $K$. xylinus cells was reported by Forng et al. (Forng et al. 1989). Son et al. (2003) identified a growth medium containing glucose and ethanol ideal for Acetobacter sp. V6 growth. Recently, de Souza et al. (2019) developed a minimal medium devoid of trace elements, amino acids, peptone and yeast extract for the growth of K. hansenii ATCC 23769.

$\mathrm{BC}$ produced from waste resources are considered as an excellent biomaterial of choice capable to replace the conventional non-sustainable materials used in electrical and sensing applications. For instance, piezoelectric materials such as fluoropolymers or lead containing piezoceramics, which generate charge separation under applied mechanical stress, are conventionally used in various engineering applications (for example, in acoustic, infrared radiation and mechanical sensors) (Rajala et al. 2018). However, the emerging need for a restorative bioeconomy demands for materials that complies with the principles of circular economy. Piezoelectric sensitivity of wood has been explored as an alternative biomaterial in sensor construction (Rajala et al. 2016). In a previous publication, we have shown $\mathrm{BC}$ films produced from conventional growth medium containing model carbon substrate showed significant piezoelectric response in the range of 5.0-20 pC/N, making $\mathrm{BC}$ a sustainable and cost-effective alternative to the conventional polyvinylidene difluoride material (Mangayil et al. 2017). Aiming towards BC production in minimal medium containing waste effluent as the sole substrate, here we report isolation, and characterization of a novel Komagataeibacter strain capable of growing in low-nitrogen conditions, and produce $\mathrm{BC}$ from glucose, glycerol and crude glycerol supplemented to both complex and minimal medium. The study progresses by demonstrating the piezoelectric sensitivities of $\mathrm{BC}$ in both normal force and bending mode measurement setups. Finally, the genome of the cellulose producer was sequenced and the genetic insights related to carbohydrate uptake mechanisms, $\mathrm{BC}$ biogenesis, and nitrogen fixation/regulation are reported.

\section{Materials and methods}

Materials and chemicals

Sodium chloride, sodium molybdate, potassium chloride, disodium hydrogen phosphate, dipotassium hydrogen phosphate, potassium dihydrogen phosphate, calcium carbonate, calcium chloride, magnesium sulphate, magnesium chloride hexahydrate, disodium hydrogen phosphate, citric acid, potassium dihydrogen phosphate, sodium dihydrogen phosphate, iron sulphate heptahydrate, sodium molybdate dihydrate, zinc sulphate heptahydrate, copper sulphate pentahydrate, cobalt chloride, ethylenediamine tetra acetic acid, nitrilotriacetic acid, manganese chloride dihydrate, bromothymol blue and oxidase test disks were purchased from Merck (Germany). Acetic acid and agar were from Fisher Scientific (UK). Glucose and casein amino acids were purchased from VWR International (Belgium). Peptone and yeast extract were from Lab M Limited (UK). Ethanol was from Altia Oyj (Finland). Cycloheximide, and cellulase from Trichoderma reesei ATCC 26921 was purchased from Sigma-Aldrich (USA). GeneJET Genomic DNA Purification Kit was purchased from Thermo Scientific (USA). Crude glycerol was generously provided by Perstrop AB (Sweden).

Isolation, characterization and culturing of the $\mathrm{BC}$ producing strain

Kombucha SCOBY (symbiotic colony of bacterial and yeast) was obtained from Sri Dhanvanthiri Probiotics Ltd, Kodaikanal, India (True Brew Kombucha tea). The SCOBY material was cut into small pieces using sterile scalpel and lysed in $50 \mathrm{ml} 1 \mathrm{X}$ Phosphate Buffered Saline (PBS; g/L, $8 \mathrm{NaCl}, 0.2 \mathrm{KCl}, 1.44$ $\mathrm{Na}_{2} \mathrm{HPO}_{4}$, and $0.24 \mathrm{KH}_{2} \mathrm{PO}_{4} ; \mathrm{pH}$ 7.4) containing $1 \%$ cellulase and incubated overnight $(\mathrm{O} / \mathrm{N})$ at $30^{\circ} \mathrm{C}$ and $180 \mathrm{rpm}$. In order to prevent the growth of the yeast cells in the symbiotic cultures, the lysis was conducted in the presence of cycloheximide $(100 \mathrm{~g} / \mathrm{L})$. The released cells were centrifuged at $1000 \mathrm{~g}$ for $10 \mathrm{~min}$ at $4{ }^{\circ} \mathrm{C}$, washed thrice with sterile PBS, resuspended and serially diluted in the buffer. To verify the presence of acetic acid bacteria, $200 \mu \mathrm{l}$ from the dilutions were plated on Glucose-Yeast Extract-Calcium carbonate agar (GYC; g/L, 40 glucose, 10 yeast extract, 30 $\mathrm{CaCO}_{3}$ and 15 agar) supplemented with 
cycloheximide and grown at $30{ }^{\circ} \mathrm{C}$ for $3-5$ days. Colonies that showed $\mathrm{CaCO}_{3}$ clear zones were individually picked, streaked on Hestrin-Schramm agar (HS; g/L, 5 peptone, 5 yeast extract, $2.7 \mathrm{Na}_{2} \mathrm{HPO}_{4}$, 1.15 citric acid and 15 agar) supplemented with $20 \mathrm{~g} / \mathrm{L}$ glucose and cycloheximide (HS-glucose). The plates were incubated at $30{ }^{\circ} \mathrm{C}$ for 5 days. Single colonies were inoculated to sterile 6-well culture plates (Argos Technologies, Cole-Parmer, US) containing HS-glucose medium and incubated at $30{ }^{\circ} \mathrm{C}$ statically for 5 days. Cellulose produced was observed by the appearance of a gelatinous pellicle on the air/liquid interface of the culture medium. The produced pellicles were lysed $\mathrm{O} / \mathrm{N}$, streaked onto HS-glucose agar and incubated at $30{ }^{\circ} \mathrm{C}$ for 5 days. The enrichment was iterated for two rounds, followed by colony and cell morphologies inspection. The isolated colony was preserved by preparing $25 \%$ glycerol stocks and storing at $-80{ }^{\circ} \mathrm{C}$.

Biochemical characterizations were conducted in MA/9 (g/L; $5.52 \mathrm{Na}_{2} \mathrm{HPO}_{4} \cdot 2 \mathrm{H}_{2} \mathrm{O}, 3.4 \mathrm{KH}_{2} \mathrm{PO}_{4}, 1$ $\mathrm{NH}_{4} \mathrm{Cl}, 0.008$ nitrilotriacetic acid, $1 \mathrm{NaCl}, 0.25$ $\mathrm{MgSO}_{4} \cdot 7 \mathrm{H}_{2} \mathrm{O}, 0.02 \mathrm{CaCl}_{2} \cdot 2 \mathrm{H}_{2} \mathrm{O}, 0.001 \mathrm{FeCl}_{3}$ and $0.2 \%$ casein amino acids) (Salmela et al. 2018), and Peptone-Yeast extract (PY) medium (Asai and Shoda 1958) (g/L, 3 peptone and 2 yeast extract). Growth only in the presence of $30 \%$ glucose, $0.35 \%$ acetic acid, $3 \%$ ethanol, and $3 \%$ ethanol with $4 \%$ acetic acid, acetate and lactate oxidation tests, and catalase test were conducted as described previously (Asai and Shoda 1958). A blank medium (PY medium) devoid of glucose, ethanol, and acetic acid was included in the study as control. Presence of oxidase was tested using oxidase test disks as per manufacturer's instructions. $\mathrm{BC}$ production in nitrogen free LGI medium $(\mathrm{g} / \mathrm{L} ; 0.2$ $\mathrm{K}_{2} \mathrm{HPO}_{4}, 0.6 \mathrm{KH}_{2} \mathrm{PO}_{4}, 0.2 \mathrm{MgSO}_{4} .7 \mathrm{H}_{2} \mathrm{O}, 0.02 \mathrm{CaCl}_{2}$ $2 \mathrm{H}_{2} \mathrm{O}, 0.002 \mathrm{Na}_{2} \mathrm{MoO}_{4} \cdot 2 \mathrm{H}_{2} \mathrm{O}, 0.01 \mathrm{FeCl}_{3} \cdot 6 \mathrm{H}_{2} \mathrm{O}, 50$ sucrose, $\mathrm{pH}$ adjusted to 4.5 using acetic acid) was tested as previously described (Florea et al. 2016). To eliminate possible nitrogen contamination from the growth medium, the cells released from the $\mathrm{BC}$ pellicles were collected (1000 $\mathrm{g}$ for $10 \mathrm{~min}$ ) and washed thrice with $1 \mathrm{X}$ PBS, before analysis of the BC production in LGI medium.

$\mathrm{BC}$ production were tested in HS and M9 minimal medium, with and without $0.2 \%$ casein amino acids. The pre-inoculum was inoculated to 6-well culture plates containing $10 \mathrm{ml}$ of respective growth medium individually supplemented with $2 \%$ glucose, pure glycerol and crude glycerol. The cultures were statically incubated at $30{ }^{\circ} \mathrm{C}$ for 10 days. The tests were conducted in duplicates and non-inoculated growth medium were included as experimental blank.

\section{BC film preparation and dry weight measurements}

The BC films were prepared as described in (Mangayil et al. 2017). Briefly, the BC sheets were collected from the cultivation vessel and rinsed with ultrapure water (Milli-Q, EMD Millipore, Germany). Bacteria entrapped within the $\mathrm{BC}$ sheets were inactivated by $\mathrm{O} / \mathrm{N}$ incubation in $0.5 \mathrm{M} \mathrm{NaOH}$ solution at $60{ }^{\circ} \mathrm{C}$. Following the treatment, sheets were repeatedly washed with ultrapure water until neutral $\mathrm{pH}$ was attained. The medium components within the cellulose sheets were removed by $\mathrm{O} / \mathrm{N}$ incubation in water at $60{ }^{\circ} \mathrm{C}$ and the washed $\mathrm{BC}$ sheets were placed in a preweighed weighing boat and oven-dried $\mathrm{O} / \mathrm{N}$ at $60{ }^{\circ} \mathrm{C}$. The BC dry weights were measured at room temperature using an analytical balance (ES 220A, Precisa, Switzerland).

Identification and phylogenetic classification of the $\mathrm{BC}$ producing isolate

For strain identification, the isolate was grown statically in loosely capped $50 \mathrm{ml}$ Corning tubes containing $10 \mathrm{ml}$ of HS-glucose medium at $30{ }^{\circ} \mathrm{C}$ for 5 days. Bacterial genomic DNA (gDNA) was isolated using GeneJET Genomic DNA Purification Kit as per the manufacturer's instructions. The $16 \mathrm{~S}$ rRNA gene amplified from the isolated gDNA was sequenced using the identification service from Macrogen (Netherlands). The 16S rRNA gene sequence amplified using primers 27F (5'-AGAGTTTGATCMTG GCTCAG-3') and 1492R (5'-TACGGYTACCTTGT TACGACTT- $\left.3^{\prime}\right)$ and sequenced with primer pairs 785F (5'-GGATTAGATACCCTGGTA-3') and 907R (CCGTCAATTCMTTTRAGTTT), can be found in the NCBI GenBank database under the accession number MT093834. Homology comparisons of the 16S rRNA gene were conducted using nucleotide BLAST (Altschul 1990) against the NCBI GenBank 16S rRNA gene sequence repository for Komagataeibacter (taxid:1434011). Multiple sequence alignment against the 16S rRNA gene sequences of Komagataeibacter type strains were conducted using ClustalW (Thompson et al. 1994). Evolutionary 
analysis against the 16S rRNA gene sequences of Komagataeibacter type strains were conducted using MEGA X using the Neighbor-Joining method with Kimura 2-parameter model and bootstrapping (1000 times) at uniform rates (Kumar et al. 2018). Bootstrapping refers to a technique for statistical estimation of the accuracy of the nodes, assisting in the reconstruction of the phylogenetic tree.

\section{Analytical techniques}

Cell density was determined as $\mathrm{OD}_{600 \mathrm{~nm}}$ measurements using a spectrophotometer (Ultraspec 500pro, Amersham Biosciences, UK). Substrate utilization, and liquid end metabolites were analyzed using HPLC equipped with $300 \mathrm{~mm} \times 8 \mathrm{~mm}$ Shodex SUGAR column (Phenomenex), SIL-20AC HT autosampler (Shimadzu), RID-10A refractive index detector (Shimadzu), and $0.01 \mathrm{M} \mathrm{H}_{2} \mathrm{SO}_{4}$ as the mobile phase. The HPLC samples were prepared as described previously (Salmela et al. 2018).

\section{Material characterization}

For material characterization, oven-dried BC films produced from MA/9 medium (see section BC film preparation and dry weight measurements) supplemented with $2 \%$ glucose, pure glycerol and crude glycerol were used. The BC films prepared from each carbon source was designated as BC-glucose, BCglycerol and $\mathrm{BC}$-crude glycerol in the material characterization section. Surfaces and cross-sectional images and X-ray diffraction patterns of the dried BC films were analyzed using a scanning electron microscope (SEM; Zeiss ULTRAPlus, Germany) and X-ray diffractometer (XRD; Empyrean multipurpose diffractometer, PANalytical B.V, US), respectively, as described previously (Mangayil et al. 2017). The thermal behavior of $\mathrm{BC}$ films was analyzed by Thermogravimetric analyzer (TG 209 F3 Tarsus, Netzsch-Gerätebau $\mathrm{GmbH}$, Germany). The weight loss from duplicate samples (size, 3.5-6.0 mg) were studied under $\mathrm{N}_{2}$ atmosphere in $30{ }^{\circ} \mathrm{C}$ to $600{ }^{\circ} \mathrm{C}$ range at heating rate of $10{ }^{\circ} \mathrm{C} / \mathrm{min}$.

Piezoelectric sensitivity measurements

Oven-dried BC films prepared from MA/9 medium containing $2 \%$ glucose and crude glycerol were used in this study (see section BC film preparation and dry weight measurements). Sensor construction, piezoelectric sensitivity measurement setup and sensitivity calculations were conducted as described previously (Mangayil et al. 2017; Sriplai et al. 2020) with slight variations. The hydrated $\mathrm{BC}$ film was sandwiched between two silver electrodes $(100 \mathrm{~nm})$ vacuum evaporated on poly(ethylene-terephthalate) (PET) film and left to dry $\mathrm{O} / \mathrm{N}$ at $45{ }^{\circ} \mathrm{C}$ resulting in a self-adhered construct. Sensitivities were measured from five different positions on the electrode while the sample was resting on the shaker plate and pressed with normal force. In addition, a polydimethylsiloxane (PDMS) ring with a $10 \mathrm{~mm}$ diameter hole was placed under the sample to allow it to bend under the dynamic force.

Genome sequencing, assembly and bioinformatics

$K$. rhaeticus ENS9a gDNA was extracted as previously mentioned (see Identification and phylogenetic classification of the BC producing isolate) and sequenced at Novogene Europe (Cambridge, UK) using Illumina Novaseq 6000. The raw reads were assembled using Trimmomatic (Bolger et al. 2014) for read trimming, SPAdes (Bankevich et al. 2012) for denovo assembly, and CAR (Lu et al. 2014) for reference-based contig assembly with $K$. rhaeticus iGEM genome (GenBank accession number, LT575493.1) sequence. Plasmids in the raw reads and the assembled contigs were identified using plasmidSPAdes (Antipov et al. 2016). Misassemblies were identified using QUAST (5.0.2) (Gurevich et al. 2013). Contig reordering, missassembly correction and gap filling were conducted using GFinisher (Guizelini et al. 2016). The scaffolds were manually linked, and the genome quality was assessed again using QUAST. The genome was annotated using RASTtk (Brettin et al. 2015) and Prokka (Seemann 2014). tRNAs were predicted using tRNAscan-SE v. 2.0 online service from Lowe lab (http://lowelab.ucsc. edu/tRNAscan-SE/, accessed on 25.02.2020) (Lowe and Chan 2016). Genes associated with cellulose synthesis, extracellular matrix formation, and substrate catabolism were identified through the SEED viewer within the RAST online service and confirmed using protein BLAST against NCBI non-redundant database. Genome based taxonomy was performed using the Type Strain Genome Server online service 
from DSMZ (https://tygs.dsmz.de/, accessed on 26.02.2020) (Meier-Kolthoff and Göker 2019). Coverage was estimated by mapping the raw reads onto the genome using Bowtie2 (Langmead and Salzberg 2012) and the .SAM files were compressed to .BAM files and indexed using SAMtools ( $\mathrm{Li}$ et al. 2009). The chromosome sequence of $K$. rhaeticus ENS9a can be found in the NCBI GenBank under the accession number CP050139 and the plasmids at CP050140 (pENS1), CP050141 (pENS2), CP050142 (pENS3), CP050143 (pENS4) and CP050144 (pENS5).

\section{Results and discussions}

Isolation, characterization and classification of the BC-producing strain

Kombucha SCOBY (symbiotic colony of bacteria and yeast) comprises of complex microbial ecosystem primarily consisting of cellulose producing acetic acid bacteria within Acetobacteraceae family, making it an excellent raw material for the strain isolation. The colonies that appeared on GYC agar were selected based on $\mathrm{CaCO}_{3}$ solubilization, a characteristic property of the members of Acetobacteraceae family. Of the 35 single colonies selected, only 14 demonstrated $\mathrm{BC}$ production capacities in the range of $0.3-2 \mathrm{~g} / \mathrm{L}$. These isolates produced both acetic acid and $\mathrm{BC}$, providing a preliminary analysis that they belong to Komagataeibacter sp. Among them, the pellicle from one isolate that produced $>1.5 \mathrm{~g} / \mathrm{L}$ BC were lysed and streaked repeatedly on HS-glucose agar. On agar plates, ENS9a colonies were small, moist, irregularly edged, white colored, pulvinated colonies that were difficult to pick using an inoculation loop (Fig. S1a). The isolate appeared as rod-shaped cells either singularly, in pairs or in chains and the cell sizes varied in range of 3-4 $\mu \mathrm{m} * 0.6-0.7 \mu \mathrm{m}$ (Fig. S1b).

The biochemical characterizations were initially performed in MA/9 medium. The isolate was able to grow in $30 \%$ glucose, but grew poorly when cultured in MA/9 medium containing ethanol and/or acetic acid. Thus, the biochemical characterization tests using ethanol and acetic acid as carbon sources were conducted in PY medium. Similar to previously reported Komagataeibacter isolates (Lin et al. 2016), ENS9a showed positive and negative results for catalase and oxidase tests, respectively. The strain did not require acetic acid for growth, oxidized acetate and lactate in PY medium and demonstrated acetic acid overoxidation (Fig. S2). The drop in the medium $\mathrm{pH}$ after a 14-day cultivation with $30 \%$ glucose (MA/ 9) and 3\% ethanol (PY) cultivations, indicated the isolate's ability to utilize the substrates for growth (Fig. S3). For cultivations in 3\% ethanol and $4 \%$ acetic acid, the medium $\mathrm{pH}$ remained stable until day 11 with a slight drop thereafter, attributing towards acid production from ethanol oxidation. When cultured in the presence of $0.35 \%$ acetic acid, the $\mathrm{pH}$ of the medium showed a slight increase after day 2 and a stable trend until the end of the cultivation period. The formation of $\mathrm{BC}$ pellicles in PY medium containing $0.35 \%$ acetic acid and its absence in the control cultivation suggests the isolate's capacity to grow under those conditions (Fig. S4). Interestingly, when grown in nitrogen-free LGI medium, ENS9a produced $\mathrm{BC}$ pellicle after 20 days of static aerobic cultivation at $30{ }^{\circ} \mathrm{C}$, indicating possible nitrogen fixation/regulation mechanisms (Fig. S5, for more details see Genome features section below).

Biochemical tests and phenotypic characteristics consistent to that reported for Komagataeibacter genus (Dellaglio et al. 2005), indicated that the strain can be affiliated to the genus. Phylogenetic analysis using the ENS9a 16S rRNA gene against the Komagataeibacter type strains positioned the isolate among $K$. rhaeticus with a $98 \%$ similarity towards $K$. rhaeticus DST GL02 ${ }^{\mathrm{T}}$ (Fig. 1).

Cellulose production in rich medium

To characterize the $\mathrm{BC}$ production profiles, K. rhaeticus ENS9a was statically grown in HS medium supplemented with $2 \%$ glucose and pure glycerol. The strain produced the highest $\mathrm{BC}$ titer (and yield) in HSglycerol $\left[2.6 \pm 0.1 \mathrm{~g} / \mathrm{L} \quad\left(1.3 \mathrm{mg} / \mathrm{g}_{\text {substrate }}\right) ;\right.$ Fig. 2a] demonstrating a substrate utilization of $41 \pm 6.0 \%$.

After the 10-day cultivation period, K. rhaeticus ENS9a completely utilized the supplemented glucose, synthesizing $1.4 \pm 0.1 \mathrm{~g} / \mathrm{L} \mathrm{BC}\left(0.7 \mathrm{mg} / \mathrm{g}_{\text {substrate }}\right)$. As expected, gluconic acid was the major liquid endmetabolite $(8.6 \pm 0.1 \mathrm{~g} / \mathrm{L}$, corresponding to $43.5 \%$ of initial glucose concentration). Glucose is an excellent carbon source for BC production, as it is easily transported into the cell and is efficiently incorporated into the cellulose biosynthetic pathway. 


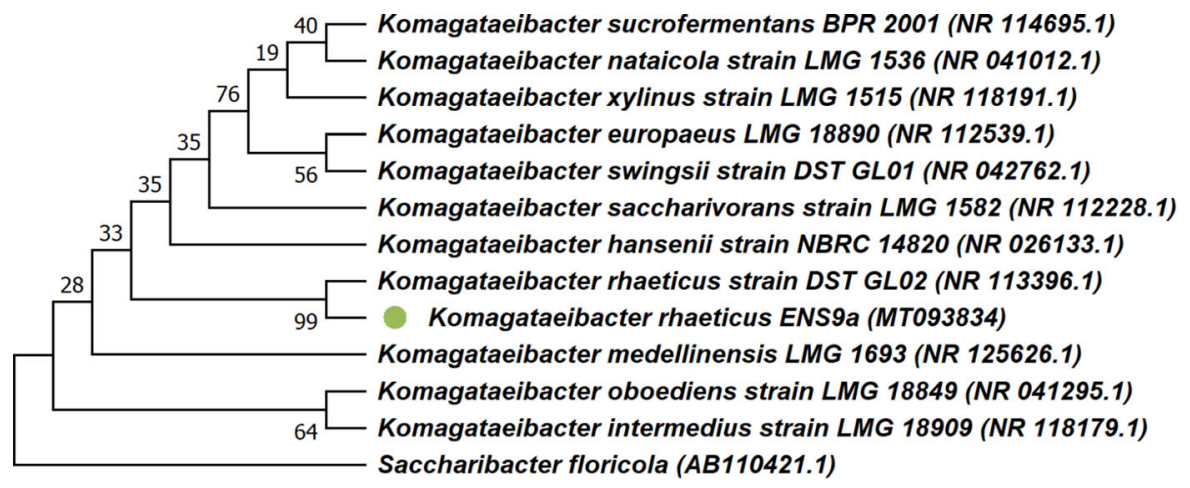

Fig. 1 16S rRNA gene-based phylogenetic relationship of $K$. rhaeticus ENS9a and Komagataeibacter type strains (NCBI accession numbers in parenthesis). The $16 \mathrm{~S}$ rRNA gene tree was

(a)
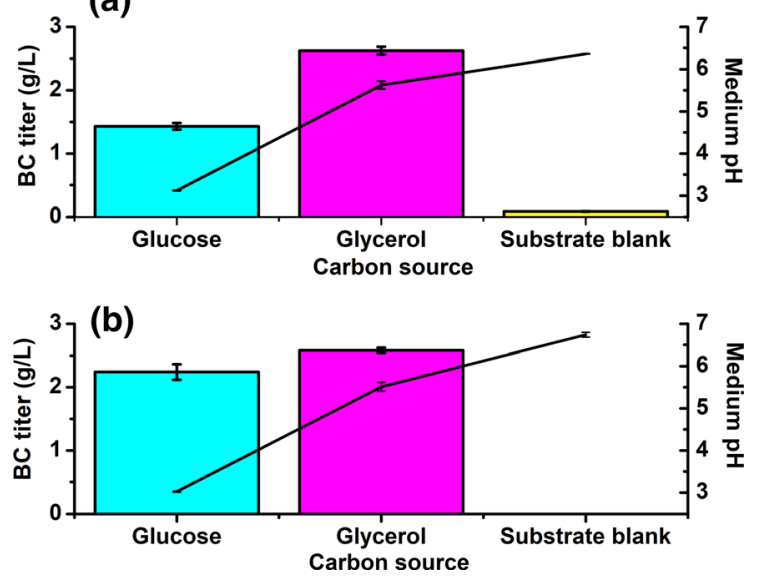

Fig. 2 BC production (bars), and $\mathrm{pH}$ (line) plots from static cultivations in a HS medium and b MA/9 medium supplemented with $2 \%$ glucose, and pure glycerol. Substrate blank was included to identify the contribution of yeast extract and peptone, and casein amino acids in HS medium and MA/9 medium, respectively, towards $\mathrm{BC}$ production. The data points represent mean experimental results and standard deviations from duplicate cultivations. In some cases, the error bars are smaller than the symbol

Komagataeibacter spp. lacks phosphofructokinase, a key enzyme of the Embden-Meyerhof pathway. Thus, primarily glucose oxidation occurs via glucose6-phosphate, entering into pentose phosphate pathway (PPP). Another oxidation route involves gluconate generation via glucose dehydrogenase activity. Gluconate is either phosphorylated to 6-phophogluconate [intermediate in Entner-Doudoroff pathway (EDP) and PPP] or oxidized to ketogluconate, which is exported extracellularly. In addition to the $\mathrm{pH}$ drop, gluconate synthesis reduces the glucose availability rooted using Saccharibacter floricola JCM 12116. K. rhaeticus ENS9a is highlighted with a green dot in the phylogenetic tree

for $\mathrm{BC}$ biosynthesis. With glycerol as substrate, the metabolic activities in Komagataeibacter spp. are supported by gluconeogenesis, Krebs cycle, PPP and EDP, without gluconic acid formation reasoning for the improved BC production.

Generally, Komagataeibacter spp. are cultivated in rich medium (Kuo et al. 2015; Lu et al. 2020) and the contribution of carbon-containing medium components (i.e. yeast extract, peptone, acetic acid and ethanol) towards BC production are often overlooked. HS medium, a conventional Komagataeibacter cultivation medium, contains peptone $(5 \mathrm{~g} / \mathrm{L})$ and yeast extract $(5 \mathrm{~g} / \mathrm{L})$, widely used growth stimulants for bacterial growth. This excess supply of amino acids and carbon can partake in gluconeogenesis positively influencing the cellular metabolic activities (Holwerda et al. 2012). The influence of such complex medium components was studied by growing the isolate in minimal medium.

Cellulose production in minimal medium

Though it is straightforward to choose a previously reported minimal media (Forng et al. 1989; Son et al. 2003; de Souza et al. 2019), we opted to use MA/9 medium as it has been proven to support the growth of gram-positive and gram-negative bacteria cultivations. The $\mathrm{BC}$ production capacities were initially studied in M9 medium with and without casein amino acids supplementation. Surprisingly, after 10-days of cultivation, growth was not observed in medium devoid of casein amino acids. However, considering the strain's ability to synthesize $\mathrm{BC}$ in $\mathrm{N}_{2}$-free LGI 
medium (that lacked amino acids) after a 20-day incubation period indicates that the absence of growth in M9 medium could be attributed to a short incubation period (10 days) (Fig. S5). Positive effects of exogenous amino acid supplementation on the growth of Komagataeibacter spp. have been previously reported (Matsuoka et al. 1996).

The $\mathrm{BC}$ production, substrate utilization and $\mathrm{pH}$ profiles from cultivations in M9 medium containing $0.2 \%$ casein amino acids (MA/9) are presented in Fig. 2b. After a 10-day incubation period, glycerol utilization improved to $89 \pm 2.4 \%$, synthesizing $2.6 \pm 0.0 \mathrm{~g} / \mathrm{L} \mathrm{BC}\left(1.3 \mathrm{mg} / \mathrm{g}_{\text {substrate }}\right)$ from pure glycerol. Absence of $\mathrm{BC}$ in the substrate blank cultivations verified that the carbon for BC synthesis is contributed solely by glycerol. With glucose as the sole carbon source, K. rhaeticus ENS9a synthesized BC with titers (and yields) of $2.2 \pm 0.1 \mathrm{~g} / \mathrm{L} \quad\left(1.1 \mathrm{mg} / \mathrm{g}_{\text {substrate }}\right)$. Unlike HS medium cultivations, growth in MA/9 medium reduced gluconic acid formation $(4.1 \pm 0.2 \mathrm{~g} / \mathrm{L}$, corresponding to $21.4 \%$ of initial glucose concentration). Improved buffering capacity is reasoned towards reduced gluconic acid formation in MA/9 cultivations (Lin et al. 2016). HS medium lacks essential nutrients such as magnesium, calcium, iron and potassium ions, that play pivotal roles in cellular metabolism (de Souza et al. 2019). Inclusion of such macro and micronutrients in the original MA/9 medium composition can positively effect the bacterial growth. BC synthesis is regulated by the enzymatic activities of diguanylate cyclase, phosphodiesterase, UDP-glucose pyrophosphorylase, and bcs operon, which are in-turn regulated by the physiological conditions in which the bacterium is cultivated. The obtained BC titers are moderate when compared to the previously published results from rich media containing other carbon-containing compounds (Table 1), suggesting its possible influence on microbial growth and BC synthesis. When grown in minimal medium, the rate-limiting step is partly determined by the carbon source of choice. For example, with glucose, substrate uptake is the limiting factor and for glycerol, the reduced flux towards gluconeogenesis route is reported as one of the bottlenecks (Ross et al. 1991). Nevertheless, substitution of conventional medium (HS medium) with MA/9 medium improved BC titers and reduced gluconic acid formation, indicating an optimal minimal growth medium for $K$. rhaeticus ENS9a.
Crude glycerol as a suitable sustainable carbon source for BC production

Waste glycerol obtained through biodiesel production processes often contains impurities such as fatty acids, salts, soaps and other organic compounds. Nevertheless, crude glycerol is considered as an cost-effect carbon source in microbial fermentation processes, offering an excellent valorization route to synthesize a variety of products (Yang et al. 2012; Mangayil et al. 2012, 2019). Here, the capacity of $K$. rhaeticus ENS9a to utilize crude glycerol as the sole carbon source for BC production was evaluated in both minimal (MA/9) and rich (HS) growth media. On comparison with HSmedium, $K$. rhaeticus ENS9a was positively modulated in buffered MA/9 medium with an improved substrate utilization and a BC titer (and yield) from $41 \pm 8.0 \%$ and $1.8 \pm 0.1 \mathrm{~g} / \mathrm{L}\left(0.8 \mathrm{mg} / \mathrm{g}_{\text {substrate }}\right.$, HS medium), to $58.5 \pm 7.5 \%$ and $2.9 \pm 0.3 \mathrm{~g} / \mathrm{L}(1.5 \mathrm{mg} /$ $\mathrm{g}_{\text {substrate }}, \mathrm{MA} / 9$ medium). The obtained BC titers are within the range of previously reported values from crude glycerol (Table 2). In contrast to the literature, it is to be noted that the titer reported in this study are obtained solely from crude glycerol in a growth medium devoid of other carbon containing compounds. To the best of our knowledge, this is the highest reported titer from an unoptimized minimal medium containing waste glycerol.

\section{Characterization of $\mathrm{BC}$ films}

The XRD analysis of BC films produced by $K$. rhaeticus ENS9a grown in MA/9 medium containing glucose, pure glycerol and crude glycerol are shown in Fig. 3a. The XRD results revealed two dominant diffraction peaks between $14.6^{\circ}$ and $17.0^{\circ}$, and between $22.7^{\circ}$ and $35.1^{\circ}$, respectively. Consistent with a previous report ( $\mathrm{Lu}$ et al. 2020), these peaks represent both the cellulose I allomorphs I $\alpha$ and I $\beta$. Furthermore, the amorphous regions were identified at peaks 22.1, 20.2 and 21.2 for BC produced from glucose, pure glycerol and crude glycerol, respectively. Though the amorphous peaks have low intensities, its presence can be seen from the unsymmetrical peak shape.

For uniformity with our previous study and to conduct a comprehensive measurement using both amorphous and crystalline regions in the XRD spectrum, the BC crystallinities in this study were 
Table 1 BC production from static growth in rich media containing glucose or pure glycerol reported in literature. Unless otherwise specified, BC production metrics, titers and productivity (in parenthesis) are reported from static cultivation in growth medium containing $20 \mathrm{~g} / \mathrm{L}$ substrate. Growth medium with different substrate concentrations are indicated with superscripts and mentioned in the footnotes

\begin{tabular}{|c|c|c|c|c|}
\hline Bacterial strain & $\begin{array}{l}\text { Growth } \\
\text { medium }\end{array}$ & Carbon-containing medium components & Production metrics $^{\mathrm{a}}$ & References \\
\hline \multicolumn{5}{|l|}{ Glucose } \\
\hline $\begin{array}{l}K . \text { intermedius } \\
\text { FST213-1 }\end{array}$ & HS & $5 \mathrm{~g} / \mathrm{L} \mathrm{YE}, 5 \mathrm{~g} / \mathrm{L}$ Pep & $2.3 \mathrm{~g} / \mathrm{L}(0.01 \mathrm{~g} / \mathrm{L} / \mathrm{h})$ & Lin et al. (2016) \\
\hline K. rhaeticus $\mathrm{PG} 2$ & HS & $5 \mathrm{~g} / \mathrm{L} \mathrm{YE}, 5 \mathrm{~g} / \mathrm{L}$ Pep & $\sim 4 \mathrm{~g} / \mathrm{L}(0.01 \mathrm{~g} / \mathrm{L} / \mathrm{h})$ & $\begin{array}{l}\text { Thorat and } \\
\text { Dastager (2018) }\end{array}$ \\
\hline K. xylinus B-12068 & $\begin{array}{l}\text { HS } \\
\text { modified }\end{array}$ & $5 \mathrm{~g} / \mathrm{L} \mathrm{YE}, 5 \mathrm{~g} / \mathrm{L}$ Pep, $3 \%$ Eth & $\begin{array}{l}7.9 \mathrm{~g} / \mathrm{L}(0.05 \mathrm{~g} / \mathrm{L} / \mathrm{h}, \text { Flasks }) \\
17.0 \mathrm{~g} / \mathrm{L}(0.1 \mathrm{~g} / \mathrm{L} / \mathrm{h}, \text { Petri dish }) \\
6.8 \mathrm{~g} / \mathrm{L}(0.04 \mathrm{~g} / \mathrm{L} / \mathrm{h}, \text { Glass } \\
\text { tray })\end{array}$ & $\begin{array}{l}\text { Volova et al. } \\
\text { (2018) }\end{array}$ \\
\hline K. hansenii JR-02 & $\begin{array}{l}\text { HS } \\
\text { modified }\end{array}$ & $2.5 \mathrm{~g} / \mathrm{L} \mathrm{YE}, 2.5 \mathrm{~g} / \mathrm{L}$ Pep, $2 \%$ Eth & $\begin{array}{l}5.0 \mathrm{~g} / \mathrm{L}(0.03 \mathrm{~g} / \mathrm{L} / \mathrm{h}) \\
8.4^{\mathrm{b}} \mathrm{g} / \mathrm{L}(0.05 \mathrm{~g} / \mathrm{L} / \mathrm{h})\end{array}$ & Li et al. (2019) \\
\hline K. rhaeticus AF1 & $\begin{array}{l}\text { HS } \\
\text { modified }^{c}\end{array}$ & $5 \mathrm{~g} / \mathrm{L} \mathrm{YE}, 5 \mathrm{~g} / \mathrm{L}$ Pep, $2 \%$ Eth & $\sim 6.7 \mathrm{~g} / \mathrm{L}(0.07 \mathrm{~g} / \mathrm{L} / \mathrm{h})$ & $\begin{array}{l}\text { Machado et al. } \\
\text { (2016) }\end{array}$ \\
\hline $\begin{array}{l}\text { Komagataeibacter } \\
\text { sp. W1 }\end{array}$ & HS & $5 \mathrm{~g} / \mathrm{L} \mathrm{YE}, 5 \mathrm{~g} / \mathrm{L}$ Pep & $1.2 \mathrm{~g} / \mathrm{L}(4 \mathrm{mg} / \mathrm{L} / \mathrm{h})$ & Wang et al. (2018) \\
\hline $\begin{array}{l}\text { K. rhaeticus } \\
\text { P } 1463\end{array}$ & HS & $5 \mathrm{~g} / \mathrm{L} \mathrm{YE}, 5 \mathrm{~g} / \mathrm{L}$ Pep & $\begin{array}{l}4.4 \mathrm{~g} / \mathrm{L}(0.04 \mathrm{~g} / \mathrm{L} / \mathrm{h}) \\
3.0 \mathrm{~g} / \mathrm{L}(0.03 \mathrm{~g} / \mathrm{L} / \mathrm{h})\end{array}$ & $\begin{array}{l}\text { Semjonovs et al. } \\
\text { (2017) }\end{array}$ \\
\hline \multicolumn{5}{|l|}{ K. hansenii $\mathrm{B} 22$} \\
\hline G. xylinus $^{\mathrm{d}}$ & $\begin{array}{l}\text { HS } \\
\text { YPD } \\
\text { AB-HS }\end{array}$ & $\begin{array}{l}5 \mathrm{~g} / \mathrm{L} \mathrm{YE}, 5 \mathrm{~g} / \mathrm{L} \text { Pep } \\
5 \mathrm{~g} / \mathrm{L} \mathrm{YE}, 5 \mathrm{~g} / \mathrm{L} \mathrm{Pep} \\
5 \mathrm{~g} / \mathrm{L} \mathrm{YE}, 5 \mathrm{~g} / \mathrm{L} \text { Pep, } 100 \mathrm{mM} \mathrm{AA}\end{array}$ & $\begin{array}{l}1.3 \mathrm{~g} / \mathrm{L}(4 \mathrm{mg} / \mathrm{L} / \mathrm{h}) \\
0.8 \mathrm{~g} / \mathrm{L}(2 \mathrm{mg} / \mathrm{L} / \mathrm{h}) \\
3.3 \mathrm{~g} / \mathrm{L}(0.01 \mathrm{~g} / \mathrm{L} / \mathrm{h})^{\mathrm{i}}, 7.2 \mathrm{~g} / \mathrm{L} \\
\quad(0.03 \mathrm{~g} / \mathrm{L} / \mathrm{h})^{\mathrm{ii}}\end{array}$ & Kuo et al. (2016) \\
\hline $\begin{array}{l}\text { K. rhaeticus } \\
\text { ENS9a }\end{array}$ & MA/9 ${ }^{\mathrm{e}}$ & - & $2.2 \mathrm{~g} / \mathrm{L}(0.01 \mathrm{~g} / \mathrm{L} / \mathrm{h})$ & This work \\
\hline \multicolumn{5}{|l|}{ Pure glycerol } \\
\hline K. rhaeticus $\mathrm{PG} 2$ & HS & $5 \mathrm{~g} / \mathrm{L} \mathrm{YE}, 5 \mathrm{~g} / \mathrm{L}$ Pep & $\begin{array}{l}\sim 6.9 \mathrm{~g} / \mathrm{L}(0.02 \mathrm{~g} / \mathrm{L} / \mathrm{h}) \\
\sim 8.7 \mathrm{~g} / \mathrm{L}(0.02 \mathrm{~g} / \mathrm{L} / \mathrm{h})^{\mathrm{f}}\end{array}$ & $\begin{array}{l}\text { Thorat and } \\
\text { Dastager (2018) }\end{array}$ \\
\hline K. xylinus B-12068 & $\begin{array}{l}\text { HS } \\
\text { modified }\end{array}$ & $5 \mathrm{~g} / \mathrm{L} \mathrm{YE}, 5 \mathrm{~g} / \mathrm{L}$ Pep, $3 \%$ Eth & $23.2 \mathrm{~g} / \mathrm{L}(0.14 \mathrm{~g} / \mathrm{L} / \mathrm{h})$ & $\begin{array}{l}\text { Volova et al. } \\
\text { (2018) }\end{array}$ \\
\hline K. hansenii JR-02 & $\begin{array}{l}\text { HS } \\
\text { modified }\end{array}$ & $2.5 \mathrm{~g} / \mathrm{L} \mathrm{YE}, 2.5 \mathrm{~g} / \mathrm{L} \mathrm{Pep}$ & $\sim 2.4 \mathrm{~g} / \mathrm{L}(0.01 \mathrm{~g} / \mathrm{L} / \mathrm{h})$ & Li et al. (2019) \\
\hline $\begin{array}{l}\text { Komagataeibacter } \\
\quad s p . W 1\end{array}$ & HS & $5 \mathrm{~g} / \mathrm{L} \mathrm{YE}, 5 \mathrm{~g} / \mathrm{L}$ Pep & $1.2 \mathrm{~g} / \mathrm{L}(4 \mathrm{mg} / \mathrm{L} / \mathrm{h})$ & Wang et al. (2018) \\
\hline CGMCC 17276 & $\mathrm{AE}$ & $\begin{array}{l}9 \mathrm{~g} / \mathrm{L} \mathrm{YE}, 5 \mathrm{~g} / \mathrm{L} \text { Pep, } 30 \mathrm{~g} / \mathrm{L} \mathrm{CSL}, 0.3 \% \\
\text { AA, } 1.5 \% \text { Eth }\end{array}$ & $4.5 \mathrm{~g} / \mathrm{L}(0.05 \mathrm{~g} / \mathrm{L} / \mathrm{h})$ & Lu et al. (2020) \\
\hline $\begin{array}{l}\text { K. rhaeticus } \\
\text { ENS9a }\end{array}$ & MA/9 ${ }^{\mathrm{g}}$ & - & $2.6 \mathrm{~g} / \mathrm{L}(0.01 \mathrm{~g} / \mathrm{L} / \mathrm{h})$ & This work \\
\hline
\end{tabular}

$H S$ Hestrin-Schramm medium; YPD Yeast extract-peptone-glucose medium; $A B$ - $H S$ Acetate buffered HS medium; $A E$, Acetate ethanol medium; YE Yeast extract; Pep peptone, Eth Ethanol; AA Acetic acid, CSL Corn steep liquor

${ }^{a}$ Productivity $(\mathrm{g} / \mathrm{L} / \mathrm{h})$ calculated by dividing the $\mathrm{BC}$ titer with the cultivation time reported in respective study. The values presented are rounded to nearest second digit. For low productivity values, the results are reported in $\mathrm{mg} / \mathrm{L} / \mathrm{h} ;{ }^{\mathrm{b}} \mathrm{Glucose} 60 \mathrm{~g} / \mathrm{L} ;{ }^{\mathrm{c}} \mathrm{Glucose} 50 \mathrm{~g} /$ $\mathrm{L} ;{ }^{\mathrm{d}}$ G. xylinus cultivated in; ${ }^{\mathrm{i}} \mathrm{HS}$ medium with $100 \mathrm{mM}$ acetic acid and $40 \mathrm{~g} / \mathrm{L}$ glucose,${ }^{\mathrm{ii}} \mathrm{HS}$ medium with $100 \mathrm{mM}$ acetic acid, $60 \mathrm{~g} /$ L glucose with a surface area/volume ratio of 0.55 ; ${ }^{\mathrm{e}}$ unoptimized minimal media; ${ }^{\mathrm{f}} 30 \%$ pure glycerol; ${ }^{\mathrm{g}}$ unoptimized minimal medium 
Table 2 BC production metrics from Komagataeibacter strains cultivated in crude glycerol as reported in literature. Unless otherwise specified, BC production metrics, i.e. titers and productivity (in parenthesis), are reported from static cultivation in growth medium containing $20 \mathrm{~g} / \mathrm{L}$ crude glycerol. Growth medium with different substrate concentrations are indicated with superscripts and mentioned in the footnotes

\begin{tabular}{|c|c|c|c|c|}
\hline Bacterial strain & $\begin{array}{l}\text { Growth } \\
\text { medium }\end{array}$ & $\begin{array}{l}\text { Carbon-containing medium } \\
\text { components }\end{array}$ & $\begin{array}{l}\text { Production } \\
\text { metrics }^{\mathrm{a}}\end{array}$ & References \\
\hline G. sacchari & HS & $5 \mathrm{~g} / \mathrm{L} \mathrm{YE}, 5 \mathrm{~g} / \mathrm{L} \mathrm{Pep}$ & $\begin{array}{l}0.1 \mathrm{~g} / \mathrm{L} \\
\quad(0.1 \mathrm{mg} / \mathrm{L} / \mathrm{h})\end{array}$ & Carreira et al. (2011) \\
\hline G. intermedius NEDO-01 & $\mathrm{HS}^{\mathrm{b}}$ & $5 \mathrm{~g} / \mathrm{L} \mathrm{YE}, 5 \mathrm{~g} / \mathrm{L}$ Pep & $\begin{array}{l}1.3 \mathrm{~g} / \mathrm{L}(0.01 \mathrm{~g} / \\
\mathrm{L} / \mathrm{h}) \\
3.4 \mathrm{~g} / \mathrm{L}(0.04 \mathrm{~g} / \\
\mathrm{L} / \mathrm{h})^{\mathrm{i}}\end{array}$ & Kose et al. (2013) \\
\hline $\begin{array}{l}\text { K. sucrofermentans DSM } \\
15973\end{array}$ & HS & $5 \mathrm{~g} / \mathrm{L} \mathrm{YE}, 5 \mathrm{~g} / \mathrm{L} \mathrm{Pep}$ & $\begin{array}{l}3.2 \mathrm{~g} / \mathrm{L}(0.01 \mathrm{~g} / \\
\mathrm{L} / \mathrm{h}) \\
13 \mathrm{~g} / \mathrm{L}(0.04 \mathrm{~g} / \\
\mathrm{L} / \mathrm{h})^{\mathrm{c}}\end{array}$ & Tsouko et al. (2015) \\
\hline G. xylinus BNKC19 & $\mathrm{HS}^{\mathrm{d}}$ & $5 \mathrm{~g} / \mathrm{L} \mathrm{YE}, 5 \mathrm{~g} / \mathrm{L}$ Pep & $\begin{array}{l}12.3 \mathrm{~g} / \mathrm{L} \\
(0.07 \mathrm{~g} / \mathrm{L} / \mathrm{h})\end{array}$ & Soemphol et al. (2018) \\
\hline$K$. saccharivorans & HS & $5 \mathrm{~g} / \mathrm{L} \mathrm{YE}, 5 \mathrm{~g} / \mathrm{L}$ Pep & $\begin{array}{l}12.6 \mathrm{~g} / \mathrm{L} \\
(0.08 \mathrm{~g} / \mathrm{L} / \mathrm{h})\end{array}$ & $\begin{array}{l}\text { Gayathri and } \\
\text { Srinikethan (2018) }\end{array}$ \\
\hline A. xylinum & HS & $5 \mathrm{~g} / \mathrm{L} \mathrm{YE}, 5 \mathrm{~g} / \mathrm{L}$ Pep & $\begin{array}{l}\sim 1.5 \mathrm{~g} / \mathrm{L} \\
\quad(4 \mathrm{mg} / \mathrm{L} / \mathrm{h})^{\mathrm{e}}\end{array}$ & Wu et al. (2019) \\
\hline G. xylinus KCСM 41431 & HS & $9 \mathrm{~g} / \mathrm{L} \mathrm{YE}, 9 \mathrm{~g} / \mathrm{L}$ Pep & $\begin{array}{l}7 \mathrm{~g} / \mathrm{L}(0.04 \mathrm{~g} / \mathrm{L} / \\
\mathrm{h})\end{array}$ & Ho Jin et al. (2019) \\
\hline $\begin{array}{l}\text { Komagataeibacter sp. nov. } \\
\text { CGMCC } 17276\end{array}$ & $A E^{f}$ & $\begin{array}{l}5 \mathrm{~g} / \mathrm{L} \text { YE, } 5 \mathrm{~g} / \mathrm{L} \text { Pep } 30 \mathrm{~g} / \mathrm{L} \mathrm{CSL}, 0.7 \% \\
\text { AA, } 0.3 \% \text { Eth }\end{array}$ & $\begin{array}{l}4.5 \mathrm{~g} / \mathrm{L}(0.05 \mathrm{~g} / \\
\mathrm{L} / \mathrm{h})^{\mathrm{i}} \\
6 \underset{\mathrm{g} / \mathrm{L}(0.06 \mathrm{~g} / \mathrm{L} /}{\mathrm{h})}\end{array}$ & Lu et al. (2020) \\
\hline G. xylinus & HS & $5 \mathrm{~g} / \mathrm{L} \mathrm{YE}, 5 \mathrm{~g} / \mathrm{L} \mathrm{Pep}$ & $\begin{array}{l}\sim 1.5 \mathrm{~g} / \mathrm{L} \\
\quad(0.01 \mathrm{~g} / \mathrm{L} / \mathrm{h}) \\
2.9 \mathrm{~g} / \mathrm{L}(0.02 \mathrm{~g} / \\
\mathrm{L} / \mathrm{h})^{\mathrm{g}}\end{array}$ & $\begin{array}{l}\text { Dikshit and Kim } \\
\text { (2020) }\end{array}$ \\
\hline K. rhaeticus ENS9a & MA $/ 9^{h}$ & - & $\begin{array}{l}2.9 \mathrm{~g} / \mathrm{L}(0.01 \mathrm{~g} / \\
\mathrm{L} / \mathrm{h})\end{array}$ & This work \\
\hline
\end{tabular}

$H S$ Hestrin-Schramm medium; AE Acetate ethanol medium; YE Yeast extract; Pep peptone, Eth Ethanol; AA Acetic acid, CSL Corn steep liquor

${ }^{a}$ Productivity $(\mathrm{g} / \mathrm{L} / \mathrm{h})$ calculated by dividing the $\mathrm{BC}$ titer with the cultivation time reported in respective study. The values presented are rounded to nearest second digit. For low productivity values, the results are reported in $\mathrm{mg} / \mathrm{L} / \mathrm{h}$; ${ }^{\mathrm{b}}$ agitated cultivation, ${ }^{\mathrm{i}}$ with carboxymethyl cellulose; ${ }^{\mathrm{c}}$ growth medium with sun flower meal hydrolysate; ${ }^{\mathrm{d}} 10 \mathrm{~g} / \mathrm{L}$ crude glycerol; ${ }^{\mathrm{e}} 25 \mathrm{~g} / \mathrm{L}$ crude glycerol; ${ }^{\mathrm{f}} 40 \mathrm{~g} / \mathrm{L}$ crude glycerol, ${ }^{\mathrm{i}} 0.3 \%$ AA, $1.5 \% \mathrm{Eth} ;{ }^{\mathrm{g}} 50 \mathrm{~g} / \mathrm{L}$ crude glycerol; ${ }^{\mathrm{h}}$ unoptimized minimal medium

calculated using a peak deconvolution method (Park et al. 2010). Although the recommended deconvolution for cellulose is to perform a Rietveld refinement with known cellulose crystal spectra (Foster et al. 2018), lack of synchrotron data led us to choose the Park et al. (2010) method (Park et al. 2010). The CI values of $\mathrm{BC}$ films produced from glucose, pure and crude glycerol were $80 \pm 3 \%, 95 \pm 1 \%$ and $69 \pm 14 \%$, respectively. It is to be noted that the CI values varies significantly depending on the measurement method. For instance, a study by Motaung and Mokhena (2015) shows that the CI values calculated using deconvolution method and peak height method for cellulose were $66 \%$ and $73 \%$, respectively (Motaung and Mokhena 2015). In another study, Thygesen et al. (2005) found that the Segal, Ruland-Vonk, Debye calculation and Rietveld refinement methods calculated the CI value of Avicel ranging from 39 to $67 \%$ (Thygesen et al. 2005). Using a similar deconvolution method, Lu et al. (2020) 

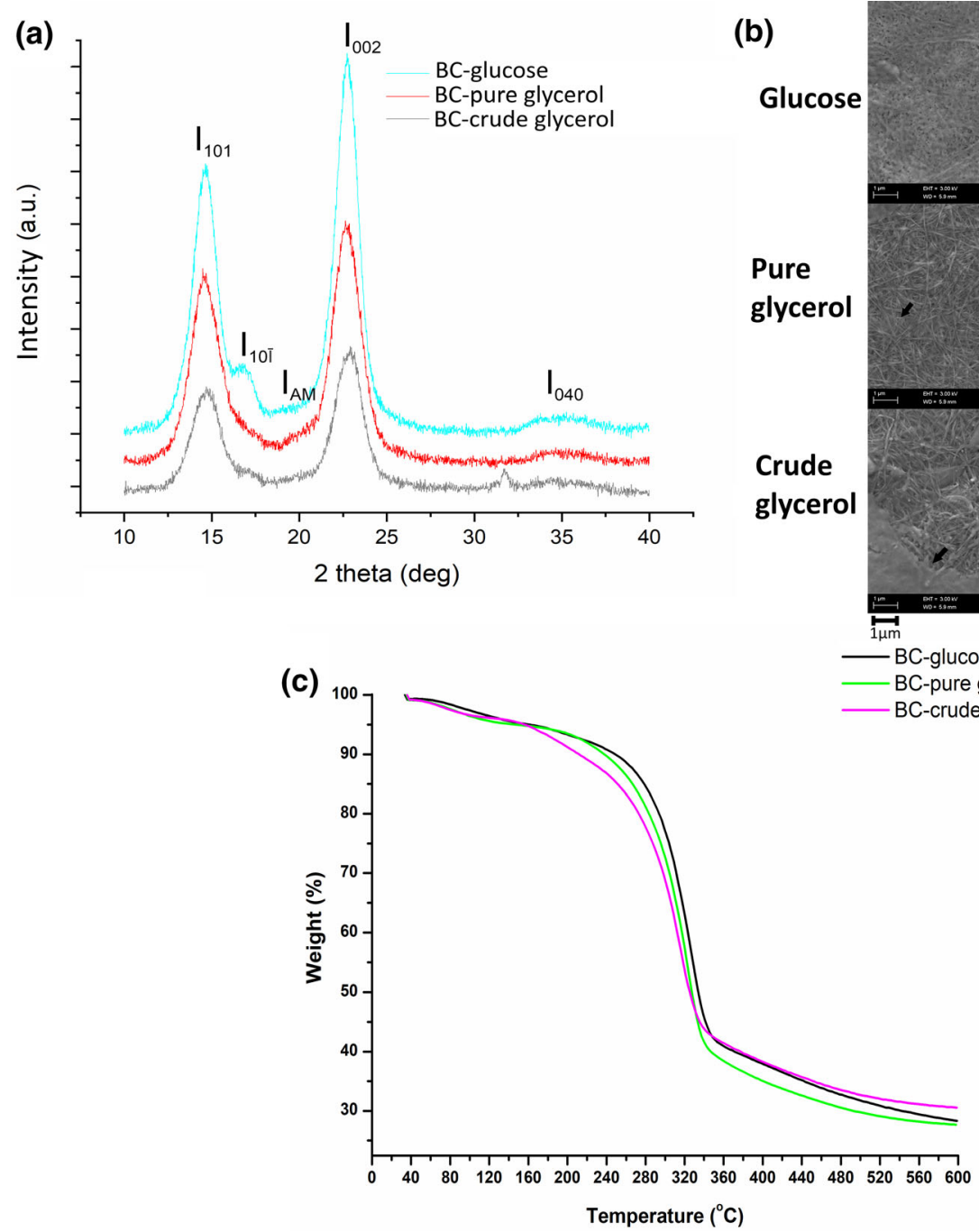

Fig. 3 a XRD diffractograms, b SEM surface and crosssectional images and $\mathbf{c}$ thermogravimetric analysis (TGA) of BC films synthesized from MA/9 medium containing $2 \%$ glucose, pure glycerol and crude glycerol. The diffraction peaks

reported a CI value of $70.5 \%$ for $\mathrm{BC}$ synthesized Komagataeibacter sp. nov. CGMCC 17276 in a medium containing glucose (Lu et al. 2020). However, the CI values obtained from the present study are comparable to that reported in our previous work (89-97\%) (Mangayil et al. 2017). Although, the peak deconvolution method offers a comprehensive assessment of cellulose crystallinity, ease of use has led the researchers to largely adopt the peak height method (or Segal method) to calculate the CI values in BC films (Segal et al. 1959; Park et al. 2010). This restricts a direct comparison with our data. Nevertheless, to (subfigure a) at $\mathrm{I}_{101}$ and $\mathrm{I}_{10} \overline{1}, \mathrm{I}_{002}$ and $\mathrm{I}_{040}$, and $\mathrm{I}_{\mathrm{AM}}$ represents the crystalline $\mathrm{I} \alpha, \mathrm{I} \beta$ and amorphous regions. The residual layer on BC films prepared from glycerol sources are indicated by arrows in subfigure $\mathbf{b}$

provide an overview and indicate the variations in CIs reported in literature, data reported from peak height method for BC films produced using glucose, pure and crude glycerol are collated in Table S1.

The surface and cross-sections of BC produced by K. rhaeticus ENS9a from different carbon sources are shown in Fig. 3b. The BC fibrils demonstrated a crisscross network with ordered interconnected layers, consistent with literature. However, an interesting observation was identified from the surface topography of the BC films (Fig. 3b, and Fig. S6). The samples produced from glycerol sources showed a 
residual layer on the surface. To identify whether such biofilm formation is a strain-specific characteristic, SEM images of BC produced by a $K$. rhaeticus strain isolated by Thorat and Dastager (2018) were analyzed. Interestingly, similar residual layer can be identified from SEM images of $\mathrm{BC}$ produced by $K$. rhaeticus strain PG2 strain grown in pure glycerol, indicating a possible strain-specific trait (Thorat and Dastager 2018). In this work, a pronounced coating was observed on BC produced from crude glycerol (Fig. S7). We speculate that such phenomenon can be caused by the impurities present in the crude glycerol fraction.

The results from thermogravimetric analysis (TGA) of BC films are presented in Fig. 3c. At the first stage $\left(30{ }^{\circ} \mathrm{C}\right.$ to $\left.120{ }^{\circ} \mathrm{C}\right)$, a primary mass loss of $4.3 \%, 4.4 \%$ and $3.1 \%$ was observed due to moisture removal for BC-glucose, BC-pure glycerol and BCcrude glycerol, respectively. The second phase involves destruction of crystalline regions and decomposition of the BC film into glucopyranose monomers. For BC-glucose, a sharp weight loss between 260 and $360{ }^{\circ} \mathrm{C}$ with an onset temperature of $292{ }^{\circ} \mathrm{C}$ indicated thermo-oxidative degradation of $\mathrm{BC}$. During this temperature, the $\mathrm{BC}$ underwent a mass loss of $60.4 \%$. The BC films produced from glycerol sources showed a similar major onset degradation at $288{ }^{\circ} \mathrm{C}$ (pure glycerol) and $282{ }^{\circ} \mathrm{C}$ (crude glycerol), albeit with slight variations in the mass loss values $(64 \%$ for BC-pure glycerol and $56 \%$ for BC-crude glycerol). The derivative thermogravimetric curve indicated a similar degradation trend for $\mathrm{BC}$-glucose and $\mathrm{BC}$-pure glycerol samples. Whereas for BC-crude glycerol films, the degradation occurred a bit earlier with a slight mass loss already before the main second phase ( 150-200 ${ }^{\circ} \mathrm{C}$ ) (Fig. S8). Nevertheless, the residual mass $(\%)$ of the tested $\mathrm{BC}$ films remained in the ranges of 27-31. These results cannot be interpreted based on the $\mathrm{CI}$ values alone as the values ranging from 69 to $96 \%$ do not correlate to the TGA data. Thermostability of BC can be influenced by varied structural properties such as molecular weight, fiber orientation, and degrees of depolymerization. The residual layer identified from the SEM analysis may also contribute towards the material's thermostability, thereby leading to slight variations the carbon yield within the tested samples (Sahoo et al. 2017). Absence of any major deviations indicates that the tested BC films demonstrate similar thermostabilities.
Piezoelectric sensitivities of BC Films

Piezoelectric sensors were constructed using the BCcrude glycerol and BC-glucose films. Piezoelectric property was not initially obtained from as-grown BCcrude glycerol films. Hypothesizing that this may be due to the residual layer on the BC surface (Fig. 3b), the sensor constructs were disassembled, BC films were washed and reassembled. This additional processing resulted in a piezoelectric response from $\mathrm{BC}$ crude glycerol samples (Fig. 4). Interestingly, we observed with our sensor materials that the electrodes naturally attach to the $\mathrm{BC}$ film firmly. If not thoroughly hydrated during disassembly, the BC could tear the evaporated metal off from the PET. We foresee this property as an advantage in bending mode measurements wherein the sensor is exposed due to the bending stress and may detach if not properly adhered.

The BC-glucose and BC-crude glycerol films demonstrated normal mode sensitivities in the range of 3-10 pC/N and 6-11 pC/N, respectively. Fukada (1955) has reported that the cellulose crystals have high d25 coefficient due to its permanent dipole momentum and the variations in the crystalline areas inside the BC films influences the material's piezoelectric coefficients. However, in this study, as the dipoles are not oriented in the same direction the overall apparent piezoelectric sensitivity cannot be estimated, leading us to study the bending mode activities of BC films. In the bending mode, the BC films showed higher piezoelectric responses with values ranging from $55-158 \mathrm{pC} / \mathrm{N}$ and $40-71 \mathrm{pC} / \mathrm{N}$ for BC-glucose and BC-crude glycerol films, respectively. The bending mode piezoelectric sensitivities from BC-glucose is higher to that observed in our previous study using BC-glucose films synthesized by K. xylinus DSM 2325 (Sriplai et al. 2020). This implies the application potential of $K$. rhaeticus ENS9a BC films in sensing applications, for instance in energy harvesting applications where bending mode sensitivities are critical. The reference material, poled PVDF, showed normal force and bending mode sensitivities of $27 \mathrm{pC} / \mathrm{N}$ and $605 \mathrm{pC} / \mathrm{N}$, respectively, corresponding to the data provided by the manufacturer.

Even though the obtained results are promising and corroborates the scope of this work, i.e. to develop and demonstrate the overall sensor properties of ecofriendly piezoelectric-responsive $\mathrm{BC}$ films, some 


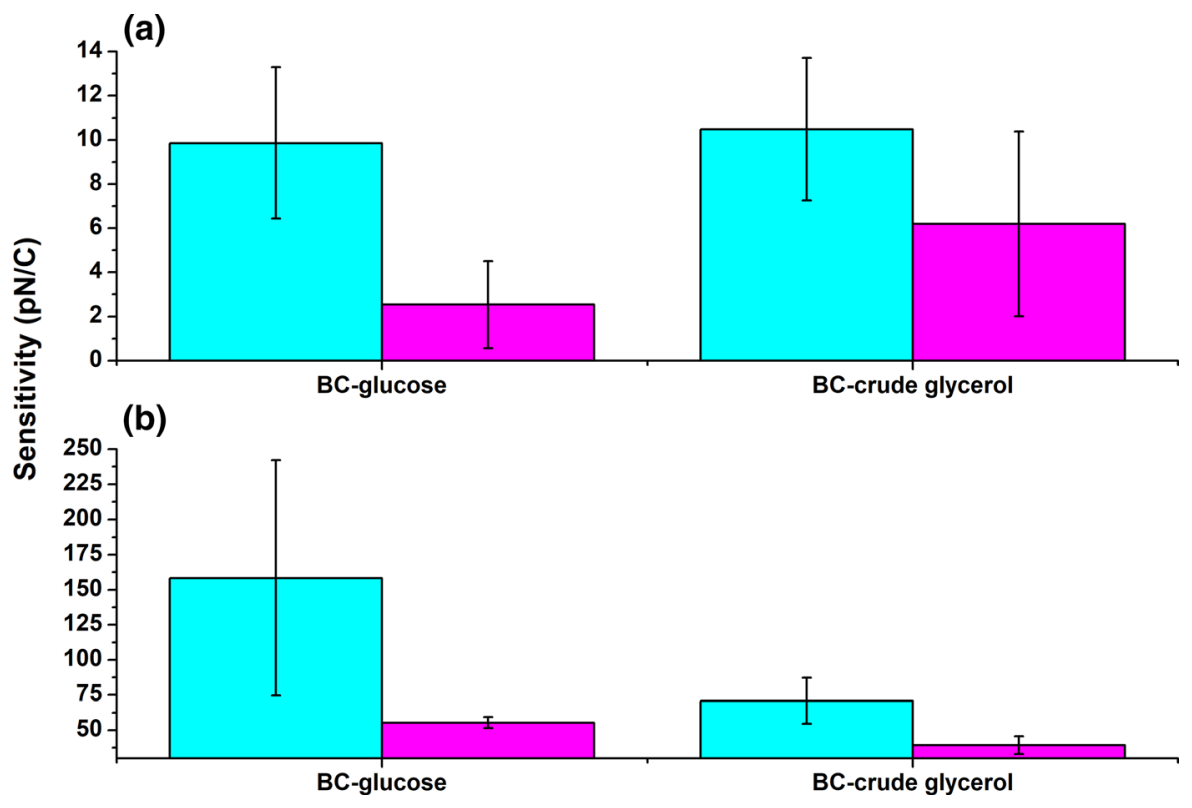

Fig. 4 Normal (a) and bending (b) mode piezoelectric sensitivities of BC films prepared from MA/9-glucose (BC-glucose) and MA/9-crude glycerol (BC-crude glycerol). Averaged values and standard deviations (error bars) from total of five excitations

sources of error that influences the precise measurements should be recognized. Firstly, the BC films used in this study were prepared in static conditions (not subjected to intentional orientation of crystalline regions). This results in $\mathrm{BC}$ sheets with randomly oriented cellulose crystals and varied thicknesses, even within the replicates. In general, the inhomogeneities in the film will definitely increase the nonreproducibility of the measurement, due to variations in the frictional forces and the applied pressure. This explains the sensitivity variances even within the replicates. Another factor is the sensor assembly. Folds and creases during manual sensor assembly can locally add strain and shear stresses to the BC, leading to measurement variations. In addition, triboelectric effect can also take place if the sample material gets to rub against the electrodes. Finally, presence of residual layers on the material surface (discussed in Characterization of $\mathrm{BC}$ films section) restricts a proper contact with the electrodes, influencing the measurements.

Nevertheless, when considering an end application using BC sensors, as with all materials, thorough characterization and calibration is crucial to ensure data accuracy and repeatability. We propose that the per sensor are presented. The blue and magenta bars represent the averaged piezoelectric sensitivity values from duplicate sensor samples prepared from respective carbon sources

errors can be tackled by comprehensive material characterization and, if required, processing using biofabrication methods to control the cellulose crystal orientations and sensor construction via an automated platform. As this work was a proof-of-concept study to demonstrate a green platform to construct piezoelectric-BC films from waste carbon, optimization of sensor construction was not delved. However, future studies on electromagnetic biofabrication to control BC nanofiber orientations and analysis using transmission electron microscope will enable us to further investigate the process.

\section{Genome features of $K$. rhaeticus ENS9a}

The above results indicate $K$. rhaeticus ENS9a as a robust wild strain capable of synthesizing $\mathrm{BC}$ in minimal medium containing crude glycerol, an economical and sustainable alternative to model sugars. Thus, the strain's genome was sequenced. General statistics of $K$. rhaeticus ENS9a genome is presented in Table S2. The genome map and KEGG classification and functional categorization of $K$. rhaeticus ENS9a are presented in Fig. 5a and b, respectively. 


\section{Predicted carbohydrate uptake and metabolism}

In gram-negative bacteria, carbohydrates are passed through the outer and cytoplasmic membrane prior to its access. This permeability is determined by porin channels. For $K$. rhaeticus ENS9a, the SEED viewer identified 10 genes that encode for putative proteins of porin B (OprB) family, among which one OprB gene (genomic position 37948-39429 bp) was homologous to glucose-selective porin OprB of Pseudomonas aeruginosa PAO1. Similar to other Komagataeibacter spp., K. rhaeticus ENS9a lacks phosphofructokinase gene incompleting the EMP, but contains the genes encoding for alternative glucose oxidation routes via PPP and EDP. In case of glycerol metabolism, genes encoding glycerol uptake facilitator proteins (at positions 62381-61542 bp and 163529-162546 bp), glycerol kinases (at positions 63916-62417 bp and 165457-166956 bp), glycerol dehydrogenase (small and large subunits at positions $35888-36274 \mathrm{bp}$ and 36274-38475 bp, respectively) and ATP-dependent dihydroxyacetone kinase (position 46480-44678 bp) entering into the gluconeogenetic, PPP, Krebs cycle and EMD pathways were identified from the genome. Validating the biochemical characterization results, alcohol and aldehyde dehydrogenases catalyzes the oxidation of ethanol to acetate. Acetate is then oxidized to acetyl-CoA through phosphorylation and transacetylation reactions contributing towards cellular biogenesis via the Krebs cycle. However, BC synthesis was observed in $K$. rhaeticus ENS9a grown in PY medium containing $0.35 \%$ acetic acid (Fig. S4) indicating that part of the carbon in acetic acid should be rerouted towards the gluconeogenetic route. Genes encoding for pyruvate synthase (acetyl-CoA to pyruvate) and phosphoenolpyruvate carboxykinase (oxaloaceticacid to phosphoenolpyruvate) were absent in the genome. However, genes encoding for NADdependent malic enzyme (catalyzing reversible malate to pyruvate reaction, at position 154247-155971 bp) and pyruvate phosphate dikinase (pyruvate to PEP, at position 405171-402496 bp) were found in the genome [nucleotide sequences in Supplementary material], hypothesizing a possible route for the carbon from Krebs cycle to enter into the gluconeogenesis route as described in Escherichia coli (Sauer and Eikmanns 2005). These insights open up new prospects in Komagataeibacter spp., for instance, controlled gene regulation of gluconeogenetic genes
Fig. 5 a Overview of $K$. rhaeticus ENS9a genome. The genome map (inside to out) chromosome size (bp), GCpercentage, CDSs on the reverse strand (orange), CDSs on the forward strand (blue), chromosome position (major ticks 500 $\mathrm{kbp}$, minor ticks $100 \mathrm{kbp}$ ), and coverage (number of reads mapping to the locus). GC-percentage (30.2-77.2\%) and coverage were calculated with $1 \mathrm{kbp}$ window size. Coverage is displayed with logarithmic scaling. The bcs operon and the surrounding genes are indicated by manually curated figures directing to its position in the genome. $\mathbf{b}$ KEGG classification and functional categorization

for efficient valorization of waste streams for BC production. In addition, the KEGG annotation and SEED search hints that the strain is capable of utilizing trehalose, starch, maltose, fructose for biomass formation.

\section{BC biogenesis machineries}

In silico analysis of $K$. rhaeticus ENS9a identified the presence of four bcs operons in the genome with varying gene compositions (Fig. 5a). The operon at position 667543-681273 bp contained the complete bcs operon (13730 bp) comprising of physically adjacent $b c s A 1, b c s B 1, b c s C 1$ and $b c s D$ genes in the order. The gene cluster was flanked with accessory genes, $b c s Z, c c p A x$ (upstream of bcs1 operon) and $b g l X$ (downstream) encoding for $\beta$-1,4-glucanase (periplasmic cellulase), cellulose complementing factor protein, and $\beta$-glucosidase, respectively. The enzymes encoded by $b c s Z$ and $b g l X$ genes, reported to participate in selective hydrolysis of non-crystalline glucan chains, are found to be crucial for BC production in K. xylinus (Kawano et al. 2008; Römling and Galperin 2015). The product of ccpAx, cellulose complementing factor protein, as the name suggests, have been reported to complement $\mathrm{BC}$ production predominantly by influencing the enzyme activities of $\mathrm{B} c s \mathrm{~B}, \mathrm{~B} c s \mathrm{C}$ and BcsD (Sunagawa et al. 2013; Römling and Galperin 2015). The second bcs operon (position 1017949-1028494 bp) comprised of fused bcs $A B 2$ and $b c s C 2$ (2036 bp downstream of bcsAB2) cluster. Genes $b c s X$ and $b c s Y$ were present in between the $b c s A B 2$ and $b c s C 2$ genes. The $b c s X$ and $b c s Y$ genes encode for putative cellulose deacylase and cellulose acylase, respectively. However, the exact biological function and their role in BC synthesis is unknown (Römling and Galperin 2015). The operon also 


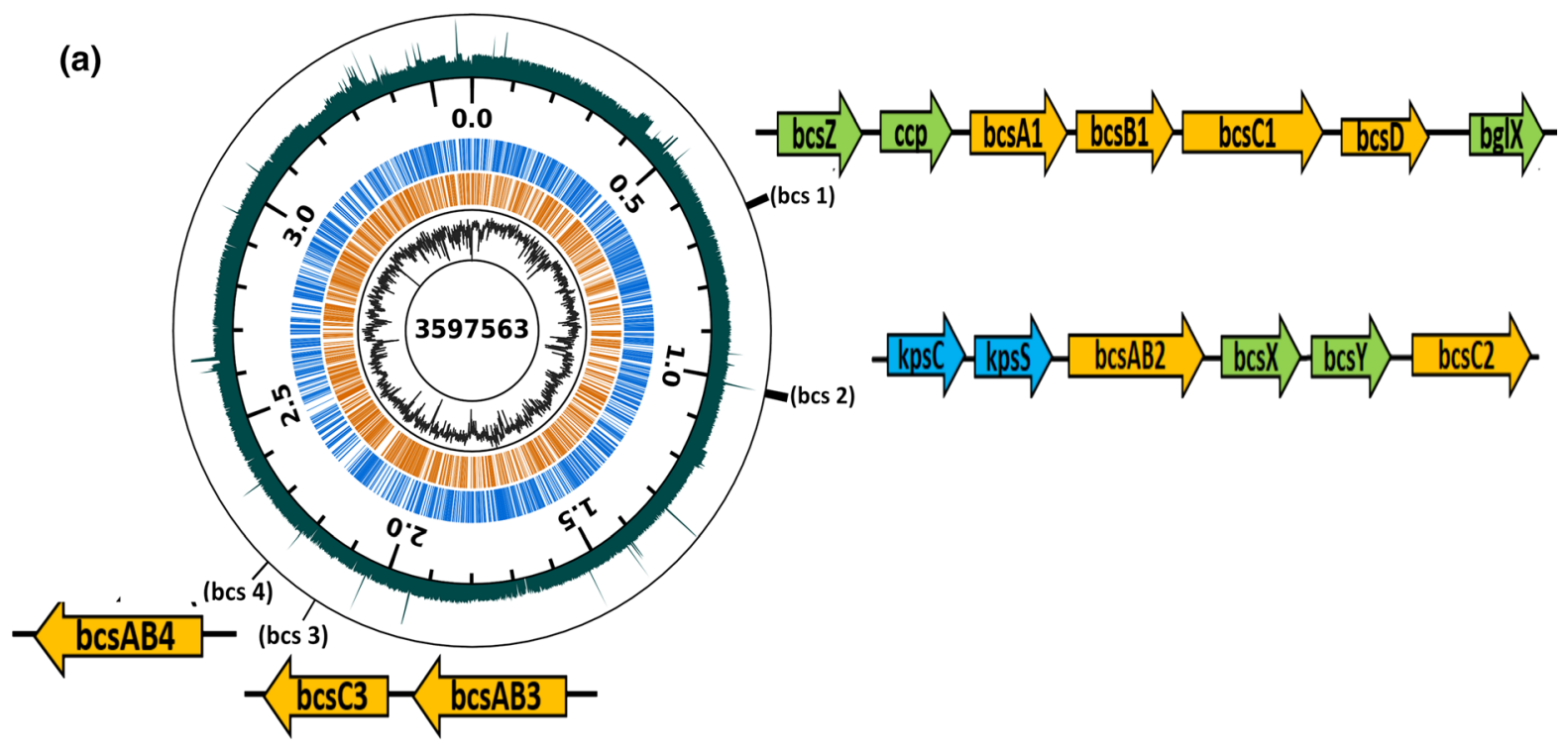

(b)

Functional catagories

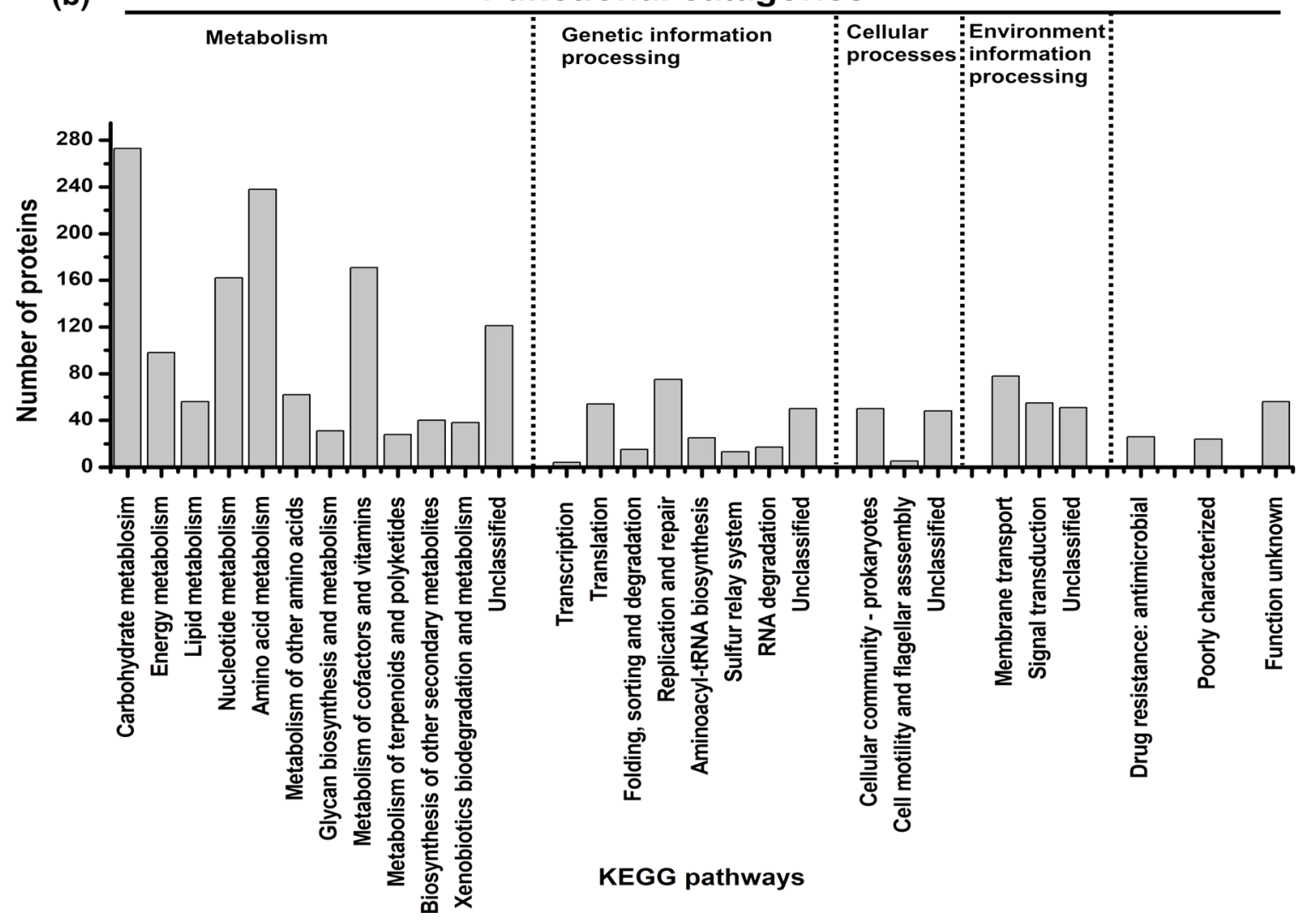


consisted of genes kpsC and kpsS that are associated with capsular polysaccharide export system. Further, a standalone copy of $b c s Z$ gene was found in position $1045306-1046328 \mathrm{bp}, 17 \mathrm{~kb}$ downstream of bcs2 operon region. The bcs3 cluster (at the genomic position 2115558-2123817 bp) contained two open reading frames corresponding to a fused cellulose synthase subunit (bcsAB3) and a bcsC3 gene, $8300 \mathrm{bp}$ downstream of $b c s A B 3$, and was not flanked with genes associated with $\mathrm{BC}$ assembly/production. Phylogenetic analysis of $b c s C$ genes identified $b c s C 3$ to be closely related to $b c s C 2$. Protein BLAST identified the amino acid similarity of $b c s C 2$ and $b c s C 3$ genes as $38.3 \%$, compared to $29-35 \%$ with bcsCl (Table S3). Unlike the other bcs operons, the fourth copy uniquely contained a fused cellulose synthase subunit, $b \operatorname{cs} A B 4$ (2229195-2233766 bp). Phylogenetically bcsAB4 is closely related to $b \operatorname{cs} A B 2$ (amino acid similarity of $65 \%$, Table S4), suggesting an integration during a duplication event in the operon (Hernández-Arriaga et al. 2019). The nucleotide sequences of bcs operon and accessory genes are given in Supplementary material.

\section{Predicted nitrogen fixation genes}

BC production in nitrogen-free LGI medium persuaded to find the gene annotations related to nitrogen fixation. We did not find genes homologous to nifHDK, which forms the main nitrogenase subunits in $G$. diazotrophicus. Use of PBS treated K. rhaeticus ENS9a cells in the test eliminates possible nitrogen contamination, indicating that the strain might contain different set of nitrogen fixation and regulatory genes. We located annotations for putative nitrogen fixation (nifU, position 169242-169805 bp), as well as nitrogen regulation genes ( $n t r B$ position 649181-650320 bp, $n t r C$ position 650354-651805 bp, ntrX position 654059-655450 bp and $n t r Y$ position $651802-654069 \mathrm{bp}$ ) that are reported to be associated with nitrogen fixation in Acetobacteraceae (James et al. 1994; Florea et al. 2016). Further, predictions for P-II family genes, reported to regulate the $n t r$ gene expressions under low nitrogen conditions in Escherichia coli, were found at positions 324216324593 bp, 565048-565386 bp and 2914441-2914779 bp. (Atkinson and Ninfa 1999) (nucleotide sequences in Supplementary material).

\section{Conclusion}

In this study, we isolated a novel bacterial strain capable of synthesizing BC from minimal medium containing crude glycerol and demonstrated piezoelectric property of the produced biomaterial. Based on the phylogenetic positioning, the isolate was affiliated to $K$. rhaeticus species and produced $\mathrm{BC}$ from glucose and glycerol sources supplemented to both minimal and complex medium. K. rhaeticus ENS9a synthesized $2.9 \pm 0.3 \mathrm{~g} / \mathrm{L}$ BC from MA/9crude glycerol cultivations. The study demonstrates normal force and bending mode piezoelectric responses in BC-crude glycerol films synthesized from MA/9 minimal medium. By addressing a material that complies with the principles of circular bioeconomy, we, for the first time, demonstrate a unique eco-friendly green production system that tackles both bioprocess waste valorization and implementation of cellulose-based alternative to replace the non-biodegradable materials, such as fluoropolymers or lead containing piezoceramics, used in sensing applications.

Author's contribution RM designed and planned the experiments. RM conducted strain isolation, characterization, and $\mathrm{BC}$ production works. RM, AJR, DG and PL performed genome assembly and bioinformatics. ES conducted the material characterization works. AP carried out the piezoelectric sensitivity measurements. ST and VS supervised the work. RM interpreted the data and wrote the original draft. AJR, AP, ES, ST and VS reviewed the manuscript.

Funding This work was supported by Academy of Finland (Project No. 323214 for RM) and Kone Foundation (Project No. 201803224 for AJR). Open access funding provided by Tampere University, Finland.

\section{Compliance with ethical standards}

Conflict of interest The authors declare that they have no conflict of interest.

Open Access This article is licensed under a Creative Commons Attribution 4.0 International License, which permits use, sharing, adaptation, distribution and reproduction in any medium or format, as long as you give appropriate credit to the original author(s) and the source, provide a link to the Creative Commons licence, and indicate if changes were made. The images or other third party material in this article are included in the article's Creative Commons licence, unless indicated otherwise in a credit line to the material. If material is not included in the article's Creative Commons licence and your 
intended use is not permitted by statutory regulation or exceeds the permitted use, you will need to obtain permission directly from the copyright holder. To view a copy of this licence, visit http://creativecommons.org/licenses/by/4.0/.

\section{References}

Altschul S (1990) Basic local alignment search tool. J Mol Biol 215:403-410. https://doi.org/10.1006/jmbi.1990.9999

Antipov D, Hartwick N, Shen M et al (2016) plasmidSPAdes: assembling plasmids from whole genome sequencing data. Bioinformatics 32:3380-3387. https://doi.org/10.1093/ bioinformatics/btw493

Asai T, Shoda K (1958) The taxonomy of acetobacter and allied oxidative bacteria. J Gen Appl Microbiol 4:289-311. https://doi.org/10.2323/jgam.4.289

Atkinson MR, Ninfa AJ (1999) Characterization of the GlnK protein of Escherichia coli. Mol Microbiol 32:301-313. https://doi.org/10.1046/j.1365-2958.1999.01349.x

Bankevich A, Nurk S, Antipov D et al (2012) SPAdes: a new genome assembly algorithm and its applications to singlecell sequencing. J Comput Biol 19:455-477. https://doi. org/10.1089/cmb.2012.0021

Bolger AM, Lohse M, Usadel B (2014) Trimmomatic: a flexible trimmer for illumina sequence data. Bioinformatics 30:2114-2120. https://doi.org/10.1093/bioinformatics/ btu 170

Brettin T, Davis JJ, Disz T et al (2015) RASTtk: a modular and extensible implementation of the RAST algorithm for building custom annotation pipelines and annotating batches of genomes. Sci Rep 5:8365. https://doi.org/10.1038/ srep08365

Carreira P, Mendes JAS, Trovatti E et al (2011) Utilization of residues from agro-forest industries in the production of high value bacterial cellulose. Bioresour Technol 102:7354-7360. https://doi.org/10.1016/j.biortech.2011. 04.081

de Souza SS, Berti FV, de Oliveira KPV et al (2019) Nanocellulose biosynthesis by Komagataeibacter hansenii in a defined minimal culture medium. Cellulose 26:1641-1655. https://doi.org/10.1007/s10570-018-2178-4

Dellaglio F, Cleenwerck I, Felis GE et al (2005) Description of Gluconacetobacter swingsii sp. nov. and Gluconacetobacter rhaeticus $\mathrm{sp}$. nov., isolated from Italian apple fruit. Int J Syst Evol Microbiol 55:2365-2370. https://doi.org/10. 1099/ijs.0.63301-0

Dikshit PK, Kim BS (2020) Bacterial cellulose production from biodiesel-derived crude glycerol, magnetic functionalization, and its application as carrier for lipase immobilization. Int J Biol Macromol. https://doi.org/10.1016/j. ijbiomac.2020.03.047

Florea M, Hagemann H, Santosa G et al (2016) Engineering control of bacterial cellulose production using a genetic toolkit and a new celluloseproducing strain. Proc Natl Acad Sci USA 113:E3431-E3440. https://doi.org/10.1073/pnas. 1522985113

Forng ER, Anderson SM, Cannon RE (1989) Synthetic medium for Acetobacter xylinum that can be used for isolation of auxotrophic mutants and study of cellulose biosynthesis.
Appl Environ Microbiol 55:1317-1319. https://doi.org/10. 1128/AEM.55.5.1317-1319.1989

Foster EJ, Moon RJ, Agarwal UP et al (2018) Current characterization methods for cellulose nanomaterials. Chem Soc Rev 47:2609-2679. https://doi.org/10.1039/C6CS00895J

Fukada E (1955) Piezoelectricity of wood. J Phys Soc Jpn 10:149-154. https://doi.org/10.1143/JPSJ.10.149

Gayathri G, Srinikethan G (2018) Crude glycerol as a costeffective carbon source for the production of cellulose by K. saccharivorans. Biocatal Agric Biotechnol 16:326-330. https://doi.org/10.1016/j.bcab.2018.08.024

Guizelini D, Raittz RT, Cruz LM et al (2016) GFinisher: a new strategy to refine and finish bacterial genome assemblies. Sci Rep 6:34963. https://doi.org/10.1038/srep34963

Gurevich A, Saveliev V, Vyahhi N, Tesler G (2013) QUAST: quality assessment tool for genome assemblies. Bioinformatics 29:1072-1075. https://doi.org/10.1093/ bioinformatics/btt086

Hernández-Arriaga AM, del Cerro C, Urbina L et al (2019) Genome sequence and characterization of the bcs clusters for the production of nanocellulose from the low $\mathrm{pH}$ resistant strain Komagataeibacter medellinensis ID13488. Microb Biotechnol 12:620-632. https://doi.org/10.1111/ 1751-7915.13376

Ho Jin Y, Lee T, Kim JR et al (2019) Improved production of bacterial cellulose from waste glycerol through investigation of inhibitory effects of crude glycerol-derived compounds by Gluconacetobacter xylinus. J Ind Eng Chem 75:158-163. https://doi.org/10.1016/j.jiec.2019.03.017

Holwerda EK, Hirst KD, Lynd LR (2012) A defined growth medium with very low background carbon for culturing Clostridium thermocellum. J Ind Microbiol Biotechnol 39:943-947. https://doi.org/10.1007/s10295-012-1091-3

Hungund BS, Gupta SG (2010) Strain improvement of Gluconacetobacter xylinus NCIM 2526 for bacterial cellulose production. Afr J Biotechnol 9:5170-5172. https://doi.org/ 10.5897/AJB09.1877

James EKK, Reis VMM, Olivares FLL et al (1994) Infection of sugar cane by the nitrogen-fixing bacterium Acetobacter diazotrophicus. J Exp Bot 45:757-766. https://doi.org/10. 1093/jxb/45.6.757

Kawano S, Tajima K, Kono H et al (2008) Regulation of endoglucanase gene (cmcax) expression in Acetobacter xylinum. J Biosci Bioeng 106:88-94. https://doi.org/10. 1263/jbb. 106.88

Kose R, Sunagawa N, Yoshida M, Tajima K (2013) One-step production of nanofibrillated bacterial cellulose (NFBC) from waste glycerol using Gluconacetobacter intermedius NEDO-01. Cellulose 20:2971-2979. https://doi.org/10. 1007/s10570-013-0050-0

Kumar S, Stecher G, Li M et al (2018) MEGA X: molecular evolutionary genetics analysis across computing platforms. Mol Biol Evol 35:1547-1549. https://doi.org/10.1093/ molbev/msy096

Kuo CH, Teng HY, Lee CK (2015) Knock-out of glucose dehydrogenase gene in Gluconacetobacter xylinus for bacterial cellulose production enhancement. Biotechnol Bioprocess Eng 20:18-25. https://doi.org/10.1007/s12257014-0316-X

Kuo C-H, Chen J-H, Liou B-K, Lee C-K (2016) Utilization of acetate buffer to improve bacterial cellulose production by 
Gluconacetobacter xylinus. Food Hydrocoll 53:98-103. https://doi.org/10.1016/j.foodhyd.2014.12.034

Langmead B, Salzberg SL (2012) Fast gapped-read alignment with Bowtie 2. Nat Methods. https://doi.org/10.1038/ nmeth.1923

Lee K-YY, Buldum G, Mantalaris A, Bismarck A (2014) More than meets the eye in bacterial cellulose: biosynthesis, bioprocessing, and applications in advanced fiber composites. Macromol Biosci 14:10-32. https://doi.org/10. 1002/mabi.201300298

Li H, Handsaker B, Wysoker A et al (2009) The sequence alignment/map format and SAMtools. Bioinformatics 25:2078-2079. https://doi.org/10.1093/bioinformatics/ btp 352

Li J, Chen G, Zhang R et al (2019) Production of high crystallinity type-I cellulose from Komagataeibacter hansenii JR-02 isolated from Kombucha tea. Biotechnol Appl Biochem 66:108-118. https://doi.org/10.1002/bab.1703

Lin S-P, Huang Y-H, Hsu K-D et al (2016) Isolation and identification of cellulose-producing strain Komagataeibacter intermedius from fermented fruit juice. Carbohydr Polym 151:827-833. https://doi.org/10.1016/j.carbpol.2016.06. 032

Lowe TM, Chan PP (2016) tRNAscan-SE on-line: integrating search and context for analysis of transfer RNA genes. Nucleic Acids Res 44:W54-W57. https://doi.org/10.1093/ nar/gkw413

Lu CL, Chen K-T, Huang S-Y, Chiu H-T (2014) CAR: contig assembly of prokaryotic draft genomes using rearrangements. BMC Bioinf 15:381. https://doi.org/10.1186/ s12859-014-0381-3

Lu T, Gao H, Liao B et al (2020) Characterization and optimization of production of bacterial cellulose from strain CGMCC 17276 based on whole-genome analysis. Carbohydr Polym 232:115788. https://doi.org/10.1016/j.carbpol. 2019.115788

Machado RTA, Gutierrez J, Tercjak A et al (2016) Komagataeibacter rhaeticus as an alternative bacteria for cellulose production. Carbohydr Polym 152:841-849. https:// doi.org/10.1016/j.carbpol.2016.06.049

Mangayil R, Karp M, Santala V (2012) Bioconversion of crude glycerol from biodiesel production to hydrogen. Int $\mathrm{J}$ Hydrog Energy 37:12198-12204. https://doi.org/10.1016/ j.ijhydene.2012.06.010

Mangayil R, Rajala S, Pammo A et al (2017) Engineering and characterization of bacterial nanocellulose films as low cost and flexible sensor material. ACS Appl Mater Interfaces 9:19048-19056. https://doi.org/10.1021/acsami. $7 \mathrm{~b} 04927$

Mangayil R, Efimova E, Konttinen J, Santala V (2019) Coproduction of 1,3 propanediol and long-chain alkyl esters from crude glycerol. N Biotechnol 53:81-89. https://doi. org/10.1016/j.nbt.2019.07.003

Matsuoka M, Tsuchida T, Matsushita K et al (1996) A synthetic medium for bacterial cellulose production by Acetobacter xylinum subsp. sucrofermentans. Biosci Biotechnol Biochem 60:575-579. https://doi.org/10.1271/bbb.60.575

McNamara JT, Morgan JLW, Zimmer J (2015) A molecular description of cellulose biosynthesis. Annu Rev Biochem 84:895-921. https://doi.org/10.1146/annurev-biochem060614-033930
Meier-Kolthoff JP, Göker M (2019) TYGS is an automated high-throughput platform for state-of-the-art genomebased taxonomy. Nat Commun 10:2182. https://doi.org/10. 1038/s41467-019-10210-3

Motaung TE, Mokhena TC (2015) Effects of mechanical fibrillation on cellulose reinforced poly(ethylene oxide). Mater Sci Appl 06:713-723. https://doi.org/10.4236/msa. 2015.68073

Park S, Baker JO, Himmel ME et al (2010) Cellulose crystallinity index: measurement techniques and their impact on interpreting cellulase performance. Biotechnol Biofuels 3:10. https://doi.org/10.1186/1754-6834-3-10

Rajala S, Siponkoski T, Sarlin E et al (2016) Cellulose nanofibril film as a piezoelectric sensor material. ACS Appl Mater Interfaces 8:15607-15614. https://doi.org/10.1021/acsami. $6 \mathrm{~b} 03597$

Rajala S, Schouten M, Krijnen G, Tuukkanen S (2018) High bending-mode sensitivity of printed piezoelectric poly(vinylidenefluoride- co -trifluoroethylene) sensors. ACS Omega 3:8067-8073. https://doi.org/10.1021/ acsomega.8b01185

Römling U, Galperin MY (2015) Bacterial cellulose biosynthesis: diversity of operons, subunits, products, and functions. Trends Microbiol 23:545-557. https://doi.org/10. 1016/j.tim.2015.05.005

Ross P, Mayer R, Benziman M (1991) Cellulose biosynthesis and function in bacteria. Microbiol Rev 55:35-58. https:// doi.org/10.1128/MMBR.55.1.35-58.1991

Sahoo G, Sarkar N, Swain SK (2017) Biomass-based nanocomposite for packaging applications. In: Jawaid M, Tahir P, Saba N (eds) Lignocellulosic fibre and biomassbased composite materials. Elsevier, Amsterdam, pp 123-146

Salmela M, Lehtinen T, Efimova E et al (2018) Metabolic pairing of aerobic and anaerobic production in a one-pot batch cultivation. Biotechnol Biofuels 11:187. https://doi. org/10.1186/s13068-018-1186-9

Sauer U, Eikmanns BJ (2005) The PEP-pyruvate-oxaloacetate node as the switch point for carbon flux distribution in bacteria: we dedicate this paper to Rudolf K. Thauer, Director of the Max-Planck-Institute for Terrestrial Microbiology in Marburg, Germany, on the occasion of his 65th. FEMS Microbiol Rev 29:765-794. https://doi.org/10. 1016/j.femsre.2004.11.002

Schramm M, Hestrin S (1954) Factors affecting production of cellulose at the air/liquid interface of a culture of Acetobacter xylinum. J Gen Microbiol 11:123-129. https://doi. org/10.1099/00221287-11-1-123

Seemann T (2014) Prokka: rapid prokaryotic genome annotation. Bioinformatics 30:2068-2069. https://doi.org/10. 1093/bioinformatics/btu153

Segal L, Creely JJJ, Martin AEE, Conrad CMM (1959) An empirical method for estimating the degree of crystallinity of native cellulose using the X-ray diffractometer. Text Res J 29:786-794. https://doi.org/10.1177/ 004051755902901003

Semjonovs P, Ruklisha M, Paegle L et al (2017) Cellulose synthesis by Komagataeibacter rhaeticus strain P 1463 isolated from Kombucha. Appl Microbiol Biotechnol 101:1003-1012. https://doi.org/10.1007/s00253-0167761-8 
Shigematsu T, Takamine K, Kitazato M et al (2005) Cellulose production from glucose using a glucose dehydrogenase gene (gdh)-deficient mutant of Gluconacetobacter xylinus and its use for bioconversion of sweet potato pulp. J Biosci Bioeng 99:415-422. https://doi.org/10.1263/jbb.99.415

Soemphol W, Hongsachart P, Tanamool V (2018) Production and characterization of bacterial cellulose produced from agricultural by-product by Gluconacetobacter strains. Mater Today Proc 5:11159-11168. https://doi.org/10. 1016/j.matpr.2018.01.036

Son H-J, Kim H-G, Kim K-K et al (2003) Increased production of bacterial cellulose by Acetobacter sp. V6 in synthetic media under shaking culture conditions. Bioresour Technol 86:215-219. https://doi.org/10.1016/S09608524(02)00176-1

Sriplai N, Mangayil R, Pammo A et al (2020) Enhancing piezoelectric properties of bacterial cellulose films by incorporation of $\mathrm{MnFe}_{2} \mathrm{O}_{4}$ nanoparticles. Carbohydr Polym 231:115730. https://doi.org/10.1016/j.carbpol. 2019.115730

Sunagawa N, Fujiwara T, Yoda T et al (2013) Cellulose complementing factor (Ccp) is a new member of the cellulose synthase complex (terminal complex) in Acetobacter xylinum. J Biosci Bioeng 115:607-612. https://doi.org/10. 1016/j.jbiosc.2012.12.021

Thompson JD, Higgins DG, Gibson TJ (1994) CLUSTAL W: improving the sensitivity of progressive multiple sequence alignment through sequence weighting, position-specific gap penalties and weight matrix choice. Nucleic Acids Res. https://doi.org/10.1093/nar/22.22.4673

Thorat MN, Dastager SG (2018) High yield production of cellulose by a Komagataeibacter rhaeticus PG2 strain isolated from pomegranate as a new host. RSC Adv 8:29797-29805. https://doi.org/10.1039/C8RA05295F

Thygesen A, Oddershede J, Lilholt $\mathrm{H}$ et al (2005) On the determination of crystallinity and cellulose content in plant fibres. Cellulose. https://doi.org/10.1007/s10570-0059001-8

Tsouko E, Kourmentza C, Ladakis D et al (2015) Bacterial cellulose production from industrial waste and by-product streams. Int J Mol Sci 16:14832-14849. https://doi.org/10. 3390/ijms160714832

Vazquez A, Foresti ML, Cerrutti P, Galvagno M (2013) Bacterial cellulose from simple and low cost production media by Gluconacetobacter xylinus. J Polym Environ 21:545-554. https://doi.org/10.1007/s10924-012-0541-3

Volova TG, Prudnikova SV, Sukovatyi AG, Shishatskaya EI (2018) Production and properties of bacterial cellulose by the strain Komagataeibacter xylinus B-12068. Appl Microbiol Biotechnol 102:7417-7428. https://doi.org/10. 1007/s00253-018-9198-8

Vuorinen T, Laurila M-M, Mangayil R, et al (2018) High resolution E-jet printed temperature sensor on artificial skin. In: IFMBE Proceedings, pp 839-842

Wang S-S, Han Y-H, Chen J-L et al (2018) Insights into bacterial cellulose biosynthesis from different carbon sources and the associated biochemical transformation pathways in Komagataeibacter sp W1. Polymers (Basel) 10:963. https://doi.org/10.3390/polym10090963

Wang J, Tavakoli J, Tang Y (2019) Bacterial cellulose production, properties and applications with different culture methods-a review. Carbohydr Polym 219:63-76. https:// doi.org/10.1016/j.carbpol.2019.05.008

Wu M, Chen W, Hu J et al (2019) Valorizing kitchen waste through bacterial cellulose production towards a more sustainable biorefinery. Sci Total Environ 695:133898. https://doi.org/10.1016/j.scitotenv.2019.133898

Yang F, Hanna MA, Sun R (2012) Value-added uses for crude glycerol - a byproduct of biodiesel production. Biotechnol Biofuels. https://doi.org/10.1186/1754-6834-5-13

Yuste L (2000) Characterization of bacterial strains able to grow on high molecular mass residues from crude oil processing. FEMS Microbiol Ecol 32:69-75. https://doi.org/10.1016/ S0168-6496(00)00015-5

Publisher's Note Springer Nature remains neutral with regard to jurisdictional claims in published maps and institutional affiliations. 